\title{
Density Functional Theory Study of Proton Mobility in Zeolites: Proton Migration and Hydrogen Exchange in ZSM-5
}

\author{
Jason A. Ryder, ${ }^{\dagger}$ Arup K. Chakraborty, ${ }^{*, \dagger, t, \S}$ and Alexis T. Bell ${ }^{\dagger, l}$ \\ Chemical and Materials Sciences Divisions, Lawrence Berkeley National Laboratory, and Departments of \\ Chemistry and Chemical Engineering, University of California, Berkeley, California 94720-1462
}

Received: December 9, 1999; In Final Form: April 18, 2000

\begin{abstract}
Acidic protons in zeolites are known to be mobile at elevated temperatures. In this study, density functional theory was used to identify the reaction pathways for proton migration in a model that represents the zeolite ZSM-5. In the absence of water, the acidic proton "hops" or migrates between two of the four O atoms surrounding an aluminum center with an activation barrier of $28 \mathrm{kcal} / \mathrm{mol}$. During proton transfer, the $\mathrm{O}$ atoms stretch closer together in order to stabilize the transition state. This is revealed by a $13.4^{\circ}$ decrease in the $\mathrm{O}-\mathrm{Al}-\mathrm{O}$ bond angle. Adsorbed water bridges the proton donor and acceptor sites, reducing the barrier height by $24 \mathrm{kcal} / \mathrm{mol}$. Hence proton migration depends heavily on the local geometry and conditions of the zeolite. We show that experimentally undetectable amounts of water can greatly influence the measured rates and apparent activation barriers. We broaden the scope of our study to consider hydrogen exchange with other gas-phase species of the form $\mathrm{RO}-\mathrm{H}\left(\mathrm{RO}=\mathrm{CH}_{3} \mathrm{O}, \mathrm{CH}_{3} \mathrm{CH}_{2} \mathrm{O}\right)$ and $\mathrm{R}-\mathrm{H}\left(\mathrm{R}=\mathrm{H}, \mathrm{CH}_{3}, \mathrm{C}_{2} \mathrm{H}_{5}, \mathrm{C}_{3} \mathrm{H}_{7}\right.$, $\mathrm{C}_{6} \mathrm{H}_{5}$ ). It is evident that to a first approximation the activation barrier increases with an increase in the polarizability of the species $\mathrm{RO}-\mathrm{H}$. For the chemical series $\mathrm{R}-\mathrm{H}$, the activation energy increases with the deprotonation energy of the interacting species $\mathrm{R}-\mathrm{H}$. We also calculate the overall reaction rate constants for proton hopping and hydrogen exchange.
\end{abstract}

\section{Introduction}

Zeolites are microporous aluminosilicates formed from oxygen-sharing silicate, $\left[\mathrm{SiO}_{4}\right]^{4-}$, and aluminate, $\left[\mathrm{AlO}_{4}\right]^{3-}$, tetrahedra. The presence of trivalent aluminum introduces a negative charge within the crystal structure. Counterions, such as $\mathrm{H}^{+}$, adsorb to oxygen sites proximate to the aluminum centers, balancing the charge. The resulting acid sites are widely accepted as the catalytic site for hydrocarbon cracking, alkylation, and isomerization reactions in zeolites.

Developing an understanding of the relationship between local zeolite structure and catalytic activity remains an aim of heterogeneous catalysis and reaction engineering research. Current experimental methods provide an average picture of the zeolite; hence, complete information on local structure and reaction mechanisms within the zeolite remains elusive. Computational methods have emerged as a powerful complementary tool to experimental methods. ${ }^{1-3}$ Using electronic structure calculations, one can obtain information pertinent to the local electronic and structural properties of the zeolite, and the potential energy hypersurface characterizing interactions with host molecules. This assists the development of rational reaction schemes and structure-function relationships. In addition, such calculations allow the estimation of key quantities that are experimentally observable (e.g., vibrational frequencies and overall reaction rate constants).

The computational expense of electronic structure calculations is high, often restricting the size of a molecular model to only those atoms vital to capturing the chemical phenomena of

\footnotetext{
$\dagger$ Department of Chemical Engineering, University of California.

Materials Science Division, Lawrence Berkeley National Laboratory.

$\S$ Department of Chemistry, University of California.

"Chemical Science Division, Lawrence Berkeley National Laboratory.
}

interest. In solids, such as zeolites, this necessitates the use of a truncated solid model or cluster approximation. Much work has been performed in the past decade to model the catalytically active sites in zeolites using such a quantum mechanical cluster approach. ${ }^{4-28}$ Many of these studies employ molecular models with imposed symmetry and relaxed geometry, approximations designed for computational efficiency. Others restrict the cluster from relaxing in ways that are inconsistent with the real zeolite. Still others have carried out calculations with periodic boundary conditions and clusters embedded in a classical electrostatic field representing the extended zeolite structure.

Experimental studies suggest that an acidic proton is not fixed to a specific zeolitic oxygen site; rather, it "hops" or migrates from one site to other neighboring sites. ${ }^{29-33}$ Variable temperature ${ }^{1} \mathrm{H}$ magic angle spinning (MAS) NMR studies of dehydrated $\mathrm{H}-\mathrm{ZSM}-5$ zeolite provide evidence that acidic protons migrate between the four oxygen atoms surrounding the tetrahedral aluminum center in the following fashion

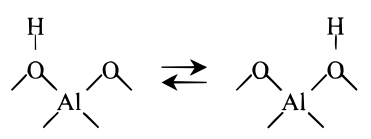

Since acidic protons are strongly bound, mobility is likely restricted to this local intrasite hopping mechanism. Theoretical calculations by Sauer et al. ${ }^{6,7}$ report an activation energy of 13 $\pm 3 \mathrm{kcal} / \mathrm{mol}$ for proton hopping in a $3 \mathrm{~T}$ atom zeolite model, which is in reasonable agreement with experimental measurements of $4-11 \mathrm{kcal} / \mathrm{mol}^{26-28}$ In this unconstrained symmetric model zeolite, the $\mathrm{O}-\mathrm{Al}-\mathrm{O}$ angle closes from $94.2^{\circ}$ at the reactant state to $74.7^{\circ}$ at the transition state. The $20^{\circ}$ change indicates that the flexibility of the $\mathrm{O}-\mathrm{Al}-\mathrm{O}$ angle plays an important role in the reaction coordinate of the proton-hopping 


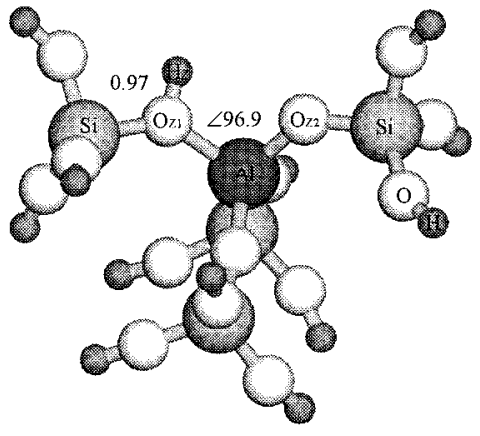

(a)

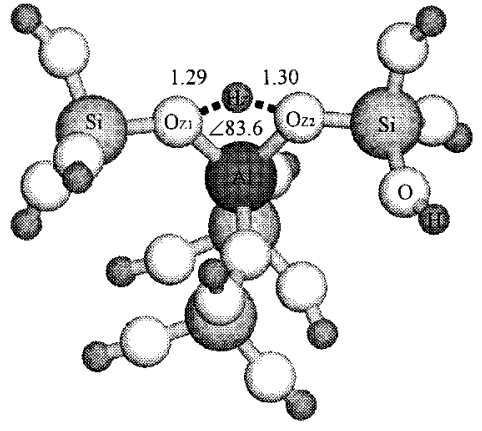

(b)

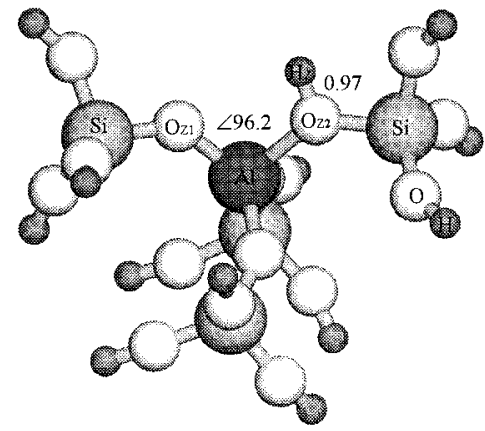

(c)

Figure 1. Equilibrium structures $(a, c)$ and transition state (b) for proton-hopping reaction.

reaction. This, in turn, makes us question whether the unconstrained geometry relaxation employed by Sauer et al. ${ }^{6,7}$ is appropriate in this case. More recent contributions by Sauer et al. ${ }^{8}$ on proton hopping in faujasite model zeolite report protonhopping barriers of 16.0, 23.5, 24.1, 25.3, 25.6, and $26.2 \mathrm{kcal} /$ mol for jumps between different $\mathrm{O}-\mathrm{O}$ pairs about the $\mathrm{Al}$ tetrahedron. In addition to employing a more extended representation of the zeolite structure, embedded cluster techniques were used to take into account long-range crystal interactions.

Higazy et al. ${ }^{34}$ have suggested that adsorbed water assists proton transfer/mobility in $\mathrm{H}-\mathrm{ZSM}-5$. On the basis of measurements of the ac conductivity of $\mathrm{H}-\mathrm{ZSM}-5$ at temperatures below $373 \mathrm{~K}$, they ascribe increases in the dielectric constant of the zeolite to water-assisted proton transfer. This provides an alternative mechanism for proton migration in zeolites, that of water-assisted proton migration:



Equation 2 can be generalized to include any gas-phase hydrogen-bearing species in the zeolite channel that can function as a proton shuttle in the zeolite. For example, simple alcohols of the form $\mathrm{RO}-\mathrm{H}$ (e.g., $\mathrm{H}_{2} \mathrm{O}, \mathrm{CH}_{3} \mathrm{OH}, \mathrm{CH}_{3} \mathrm{CH}_{2} \mathrm{OH}$, etc.) or hydrogen and alkanes of the form $\mathrm{R}-\mathrm{H}$ (e.g., $\mathrm{H}_{2}, \mathrm{CH}_{4}, \mathrm{C}_{2} \mathrm{H}_{6}$, etc.) have been shown to participate in exchange with zeolites at various temperatures.

In this work, density functional theory was used to investigate the mobility of acidic protons in $\mathrm{H}-\mathrm{ZSM}-5$ zeolite. We consider the migration of an acidic proton between two of four oxygen sites surrounding an aluminum center in a model zeolite. In contrast to previous studies, we use a larger cluster model in which the exterior atoms are constrained to preserve the geometric integrity of the zeolite. Using this constrained cluster formalism, we then examine the mechanism of local proton migration in $\mathrm{H}-\mathrm{ZSM}-5$ with and without the introduction of gas-phase hydrogen-bearing species $\mathrm{RO}-\mathrm{H}\left(\mathrm{RO}=\mathrm{OH}, \mathrm{CH}_{3} \mathrm{O}\right.$, $\left.\mathrm{CH}_{3} \mathrm{CH}_{2} \mathrm{O}\right)$ and $\mathrm{R}-\mathrm{H}\left(\mathrm{R}=\mathrm{H}, \mathrm{CH}_{3}, \mathrm{C}_{2} \mathrm{H}_{5}, \mathrm{C}_{3} \mathrm{H}_{7}, \mathrm{C}_{6} \mathrm{H}_{5}\right)$. Using absolute rate theory, we provide an estimation the overall reaction rate constants for proton hopping and hydrogen exchange. Our results suggest that the experimental observations for proton migration may be rationalized by the presence of experimentally undetectable amounts of residual water in the zeolite.

\section{Theoretical Methods}

Quantum chemical calculations are performed on a model zeolite system. We represent the protonated zeolite using a 34atom cluster, as shown in Figure 1a. The cluster contains an $\mathrm{Al}$ atom surrounded by shells of $\mathrm{O}$ and $\mathrm{Si}$ atoms. The terminal $\mathrm{O}$ atoms are fixed in their crystallographic positions, as reported by Olson et al.; ${ }^{35}$ hence, no symmetry constraints were used for any of the studied structures. Dangling bonds are terminated by $\mathrm{H}$ atoms located $1.0 \AA$ from each terminal $\mathrm{O}$ atom in the direction of the next $\mathrm{T}$ (tetrahedral) site, where a $\mathrm{T}$ site is an $\mathrm{Al}$ or $\mathrm{Si}$ atom. The overall geometry for the model is based on that of a T12 crystallographic site of ZSM-5. The anionic cluster is charge-compensated by a proton placed at one of the four $\mathrm{O}$ atoms surrounding the $\mathrm{Al}$ atom.

Geometry optimization calculations for minimum energy and transition-state structures were performed using nonlocal, gradient-corrected density-functional theory (DFT). ${ }^{36}$ Calculations were carried out to search for minima (i.e., reactants, products, and adsorbed structures) and saddle points (i.e., transition-state structures). Three different functionals were used to represent the effects of exchange and correlation in the proton-hopping reaction: Becke's 3-parameter exchange with correlation functionals of Lee, Yang, and Parr (B3LYP); Becke's Half and Half exchange with correlation functionals of Lee, Yang, and Parr (BH\&HLYP); and Becke's 1988 exchange with correlation functionals of Perdew and Wang (BPW91)..$^{37-41}$ The first two methods employ hybrid functionals, which combine HartreeFock exchange with the Becke 1988 exchange functional. ${ }^{37}$ The main difference between the two functionals lies in the weighting of exchange terms. B3LYP has become the functional of choice for calculating equilibrium structures for large systems. ${ }^{9}$ However, the BH\&HLYP functional has been shown to give more accurate determination of transition-state energies comparable to those attained from second-order Møller-Plesset perturbation theory (MP2). ${ }^{42}$ Since we are interested in transition states in this study, we rely primarily on the latter hybrid method.

Basis sets at the $6-31 \mathrm{G}$ or double- $\zeta$ level were used on all atoms. Diffuse and polarization functions were added to all atoms, with the exception of terminal $\mathrm{OH}$ groups. While computationally expensive due to the $N^{3}$ scaling of the methods (where $N$ is the number of basis functions), inclusion of diffuse functions is vital to capturing the long-range behavior of hydrogen bonding within the zeolite. No corrections were made for basis-set superposition error. Zero-point energy corrections were computed from the vibrational modes. All calculations were carried out using the Jaguar 3.5 suite of programs (Schrödinger, Inc.). ${ }^{43}$ 
TABLE 1: Selected Bond Lengths (̊̊) and Angles (deg) of Equilibrium Structures and the Transition State for the Proton-Hopping Reaction

\begin{tabular}{|c|c|c|c|c|c|c|c|c|c|}
\hline \multirow[b]{2}{*}{ method } & \multicolumn{3}{|c|}{ (a) equilibrium structure } & \multicolumn{3}{|c|}{ (b) transition state } & \multicolumn{3}{|c|}{ (c) equilibrium structure } \\
\hline & DFT-BH\&HLYP & DFT-B3LYP & $\mathrm{HF}$ & DFT-BH\&HLYP & DFT-B3LYP & $\mathrm{HF}$ & DFT-BH\&HLYP & DFT-B3LYP & $\mathrm{HF}$ \\
\hline basis set & $6-31 G^{* *++}+$ & $6-31 \mathrm{G} * *++$ & DZP & $6-31 G^{* *++}+$ & $6-31 G^{* *++}+$ & DZP & $6-31 \mathrm{G}^{* *++}+$ & $6-31 \mathrm{G}^{* *++}+$ & DZP \\
\hline cluster size & $5 \mathrm{~T}$ & $5 \mathrm{~T}$ & $3 \mathrm{~T}$ & $5 \mathrm{~T}$ & $5 \mathrm{~T}$ & $3 \mathrm{~T}$ & $5 \mathrm{~T}$ & $5 \mathrm{~T}$ & $3 \mathrm{~T}$ \\
\hline reference & this work & this work & 6,7 & this work & this work & 6,7 & this work & this work & 6,7 \\
\hline $\mathrm{O}_{\mathrm{Z} 1}-\mathrm{Al}-\mathrm{O}_{\mathrm{Z} 2}(\mathrm{deg})$ & 96.9 & 96.2 & 94.2 & 83.6 & 83.3 & 74.7 & 96.1 & 95.6 & 94.2 \\
\hline$r\left(\mathrm{O}_{\mathrm{Z} 1}-\mathrm{H}_{\mathrm{Z}}\right)(\AA)$ & 0.97 & 0.97 & 0.9524 & 1.29 & 1.29 & 1.204 & 2.56 & 2.54 & \\
\hline$r\left(\mathrm{O}_{\mathrm{Z} 2}-\mathrm{H}_{\mathrm{Z}}\right)(\AA)$ & 2.62 & 2.60 & & 1.30 & 1.30 & 1.204 & 0.97 & 0.97 & 0.9524 \\
\hline$r\left(\mathrm{Al}-\mathrm{O}_{\mathrm{Z} 1}\right)(\AA)$ & 1.86 & 1.86 & 1.943 & 1.78 & 1.78 & 1.842 & 1.68 & 1.68 & 1.712 \\
\hline$r\left(\mathrm{Al}-\mathrm{O}_{\mathrm{Z} 2}\right)(\AA)$ & 1.68 & 1.68 & 1.712 & 1.77 & 1.78 & 1.842 & 1.86 & 1.85 & 1.943 \\
\hline$E_{\text {Act }}(\mathrm{kcal} / \mathrm{mol})$ & & & & 32.3 & 25.8 & $13 \pm 3$ & & & \\
\hline$V_{\mathrm{TST}}\left(\mathrm{cm}^{-1}\right)$ & & & & $1785 \mathrm{i}$ & & $1520 \mathrm{i}$ & & & \\
\hline
\end{tabular}

Vibrational modes of adsorbed complexes and transition-state structures were computed for those atoms whose normal modes change most during reaction, and therefore contribute to the zero-point energy correction and prexponential factor. In Figure 1 these include the proton donor and acceptor $\mathrm{O}$ atoms of the Brønsted acid site, denoted $\mathrm{O}_{\mathrm{Z} 1}$ and $\mathrm{O}_{\mathrm{Z} 2}$, respectively, the acidic proton, $\mathrm{H}_{Z}$, and any gas-phase or adsorbed species interacting with the site (e.g., $\mathrm{R}-\mathrm{H}^{\prime}$ ).

Overall reaction rate constants were computed using standard statistical mechanics and absolute rate theory. ${ }^{44}$ We use the harmonic approximation and include the contributions of the translational, rotational, and vibrational partition functions of all gaseous species participating in the reaction and the vibrational contribution due to the zeolite cluster. Since the zeolite cluster is part of a solid, translational and rotational partition functions for the zeolite were assumed to be equal in the reactant and transition state. All molecular structures were assumed to be in the ground-state electronic configuration.

For the case of the proton-hopping reaction, the reaction rate constant can be expressed on a per site basis as

$$
k=\left(\frac{k_{\mathrm{B}} T}{h}\right) \frac{q_{\mathrm{TS}, \mathrm{vib}}^{\ddagger}}{q_{\mathrm{H}^{+} \mathrm{OZ}^{-}, \mathrm{vib}}} \mathrm{e}^{-E_{\mathrm{Act}} / R T}
$$

where $k_{\mathrm{B}}$ is Boltzmann's constant, $h$ is Planck's constant, and $E_{\text {Act }}$ is the activation barrier including zero-point energy (ZPE) corrections. In eq 3 we have written the vibrational partition function for the transition-state structure and equilibrium Brønsted acid site as $q_{\mathrm{TS}, \text { vib }}^{\ddagger}$ and $q_{\mathrm{H}^{+}} \mathrm{OZ}^{-}$,vib, respectively. A similar expression can be written for the overall reaction rate constant for hydrogen exchange between an adsorbed species, denoted $\mathrm{RH}^{\prime}$, and zeolite

$$
k=\left(\frac{k_{\mathrm{B}} T}{h}\right) \frac{q_{\mathrm{TS}, \mathrm{vib}}^{\ddagger}}{q_{\mathrm{RH}^{\prime}-\mathrm{H}^{+} \mathrm{OZ}^{-}, \mathrm{vib}}} \mathrm{e}^{-E_{\mathrm{Act}} / R T}
$$

Again the rate is calculated on a per site basis. Finally, we write the overall reaction rate constant for the hydrogen exchange reaction between a hydrogen-bearing gas-phase species, such as dihydrogen or methane, and zeolite

$$
k=\left(\frac{N_{\mathrm{A}} V k_{\mathrm{B}} T}{h}\right) \frac{q_{\mathrm{TS}, \mathrm{vib}}^{\ddagger}}{q_{\mathrm{RH}^{\prime}, \text { rans }} q_{\mathrm{RH}^{\prime}, \mathrm{rot}} q_{\mathrm{RH}^{\prime}, \mathrm{vib}} q_{\mathrm{H}^{+} \mathrm{OZ}^{-}, \mathrm{vib}}} \mathrm{e}^{-E_{\mathrm{Act}} / k_{\mathrm{B}} T}
$$

where $N_{\mathrm{A}}$ is Avogadro's number and $V$ is the molar volume of the system. Note that we have included the translational, rotational, and vibrational partition functions of the gas-phase species.

\section{Results and Discussion}

Proton-Hopping Reaction. In the simplest case, we consider proton migration to proceed via short-range "hops" between the four oxygen atoms surrounding the tetrahedral $\mathrm{Al}$ center. From our zeolite cluster model, we choose two equilibrium oxygen sites between which to probe the reaction pathway for proton hopping. Although the protons can jump between all four oxygen positions (for a total of six different jump paths), only one path has been studied so far. The sites are chosen because of their accessibility to each other through the main channel of ZSM-5. The binding energy of a proton at these two sites differs in energy by 3.2 and $3.6 \mathrm{kcal} / \mathrm{mol}$ for calculations using DFTB3LYP and DFT-BH\&HLYP, respectively.

The equilibrium structures and transition-state complex for the proton-hopping reaction in $\mathrm{H}-\mathrm{ZSM}-5$ are shown in Figure 1. Parts a and c of Figure 1 correspond to local minima, whereas Figure $1 \mathrm{~b}$ is the structure of the transition state for proton hopping between the two equilibrium states. We define the activation energy for proton hopping, $E_{\text {Act }}$, as the difference in energy between the equilibrium structure and the transition state. These values, uncorrected for zero-point energy, are 32.3, 25.9, and $20.5 \mathrm{kcal} / \mathrm{mol}$ for calculations using BH\&HLYP, B3LYP, and BPW91 density functionals, respectively. Zero-point energy (ZPE) corrections reduce the reported energy barriers by 4.3 $\mathrm{kcal} / \mathrm{mol}$. The imaginary frequency associated with the transition state is $1785 \mathrm{i} \mathrm{cm}^{-1}$, computed using BH\&HLYP. A summary of selected bond lengths and angles for local proton hopping in ZSM-5 is reported in Table 1.

Figure 2 gives the energy along the reaction coordinate for the proton-hopping reaction. Points along the minimum energy path, defined as that corresponding to the steepest ascent along the potential energy hypersurface, were computed by optimizing the geometry of the cluster model with relaxation of the acidic proton restricted to the plane perpendicular to the line containing atoms $\mathrm{O}_{\mathrm{Z1}}$ and $\mathrm{O}_{\mathrm{Z2}}$. Note that the greatest difference in energy computed using the three density functionals lies in the transition-state region. This results from the different methods of treating the exchange and correlation energy in each of the functionals, which are not parametrized to yield accurate saddle points (i.e., transition states). For reasons of comparison, additional geometry optimization calculations were carried out at the Hartree-Fock (HF) and MP2 levels of theory for the reactant, product, and transition state of the proton-hopping reaction. The activation energy computed using Hartree-Fock theory is the highest of all methods at $41.4 \mathrm{kcal} / \mathrm{mol}$, consistent with the notion that HF theory overlooks the correlation energy. A corresponding value of $35.7 \mathrm{kcal} / \mathrm{mol}$ is found using MP2 methods. The difference in energy barriers computed using MP2 and DFT-BH\&HLYP methods is small, only $3.4 \mathrm{kcal} / \mathrm{mol}$. The difference is more dramatic for the nonhybrid functional BPW91, which differs from the MP2 energy by $15.2 \mathrm{kcal} / \mathrm{mol}$. This agrees with previous studies that suggest hybrid functionals, 


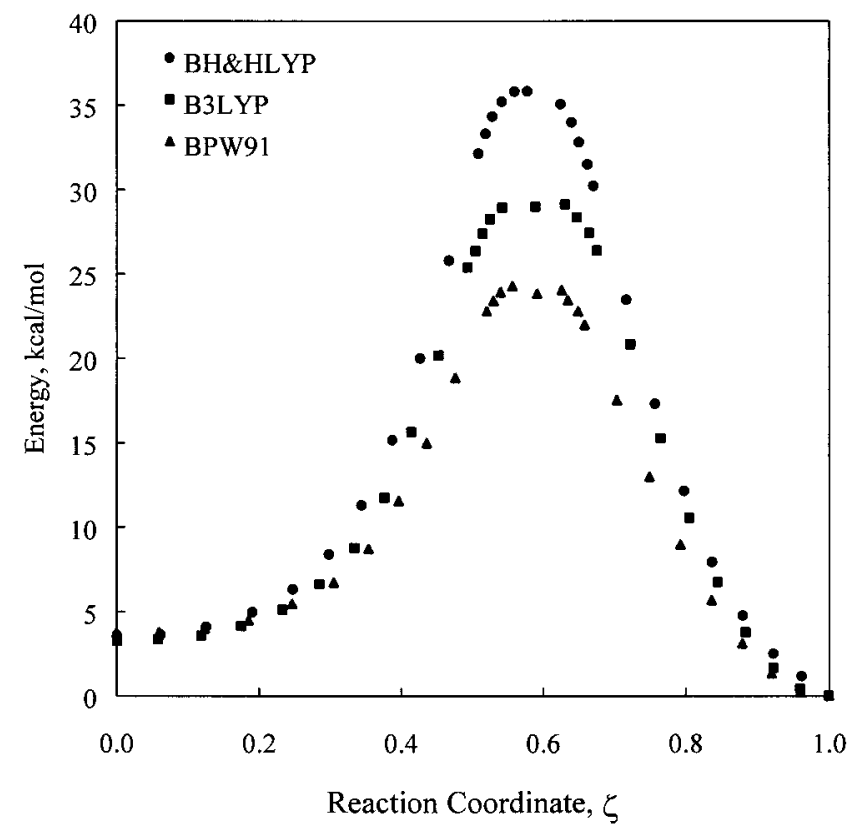

Figure 2. Energy versus reaction coordinate for proton-hopping reaction.

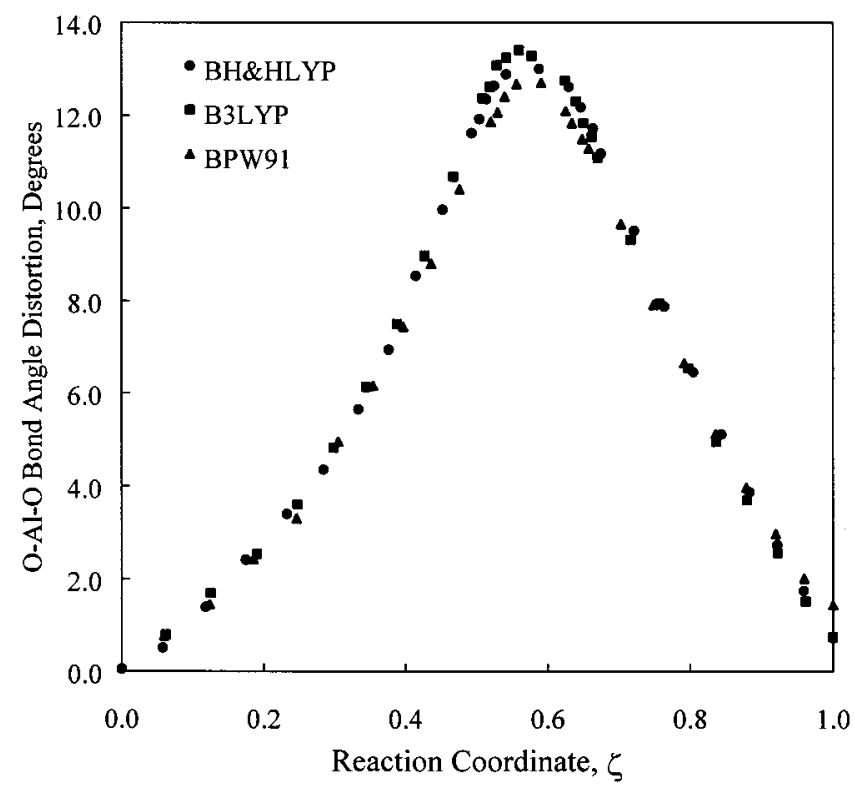

Figure 3. $\mathrm{O}-\mathrm{Al}-\mathrm{O}$ angle versus reaction coordinate for protonhopping reaction.

which incorporate exact exchange, perform better than nonhybrids for transition-state calculations.

Figure 3 illustrates how the energy and the $\mathrm{O}-\mathrm{Al}-\mathrm{O}$ angle vary as the reaction proceeds. During the proton-hopping reaction, the $\mathrm{O}-\mathrm{Al}-\mathrm{O}$ closes by $13.4^{\circ}$ from reactant state to the transition state and then relaxes to reach the product state. This is uniform for all three density functionals and suggests that the $\mathrm{O}$ atoms stretch closer together in order to stabilize the transition state. The constraints imposed on the exterior of the cluster prevent complete relaxation of the $\mathrm{O}-\mathrm{Al}-\mathrm{O}$ angle. The behavior of the $\mathrm{O}-\mathrm{Al}-\mathrm{O}$ angle suggests that proton hopping in zeolites is greatly facilitated by deformation of the zeolite framework. Therefore, it would be inappropriate to carry out dynamic studies without explicit account of framework motion. Also, from the standpoint of kinetic studies, not imposing constraints that prevent complete geometry relaxation (e.g., refs 6 and 7) would allow easier access of the proton from the donor site to the acceptor site, thus artificially lowering the activation barrier to proton hopping.

A comparison of our results with those reported by Sauer et al. ${ }^{6,7}$ based on Hartree-Fock calculations is given in Table 1. In contrast to the asymmetric, constrained cluster used in the present study, Sauer et al. used a symmetric 3T atom model in which all atoms were relaxed to optimize the transition-state geometry. A notable difference in geometry of the two models is found upon comparing the $\mathrm{O}-\mathrm{Al}-\mathrm{O}$ angle at the transition state. Sauer et al. obtained a value of $74.7^{\circ}$, whereas our calculations give $83.3-83.6^{\circ}$, a difference of $11^{\circ}$. Consistent with this, Sauer et al. report an activation energy of $13 \pm 3$ $\mathrm{kcal} / \mathrm{mol}$ for proton transfer. Though this value is closer to the experimental results, ${ }^{29,30}$ we suggest that this is fortuitous since complete relaxation of the $\mathrm{O}-\mathrm{Al}-\mathrm{O}$ angle seems inappropriate. Our aim in restricting the external atoms of the model zeolite cluster is to preserve the overall structure of the solid ZSM-5 while allowing flexibility to the interior region of the catalytic site where the reaction occurs. We believe this is realistic because reactions cause local geometric changes. We will therefore explore other mechanisms for proton hopping shortly.

To date, there are no direct experimental data on the flexibility of the zeolite crystal framework. On the basis of the large geometric and energetic differences seen from modeling proton migration using a symmetric, relaxed cluster and asymmetric constrained cluster, the effects of framework flexibility are crucial for a full understanding of local zeolite chemistry. Differences in effective pore dimensions computed from crystallographic data and those deduced from molecular sieving properties lend support to the thermally activated breathing motion of the zeolite pores at elevated temperatures. These breathing motions have been studied by Deem et al. ${ }^{45}$ for the aperture $\mathrm{O}-\mathrm{O}$ distances across the 10 -membered ring in ZSM5. On the basis of a crystal dynamics approach, they found a maximum standard deviation in the aperture $\mathrm{O}-\mathrm{O}$ distances of $0.1901 \AA$ at $550 \mathrm{~K}$, where the mean pore diameter was taken as $8.1011 \AA$. Given the relationship of pore diameter to the circumference, $\pi d$, this $2.3 \%$ deviation corresponds to a 0.062 $\AA$ expansion/contraction between pairs of nearest-neighbor $\mathrm{O}$ atoms due to the breathing motion. Our results show that the $\mathrm{O}-\mathrm{O}$ distance changes from $2.65 \AA$ at the reactant state to 2.37 $\AA$ at the transition state, a difference of $0.28 \AA$. We conclude that the concerted motion of the proton from the proton donor to the proton acceptor $\mathrm{O}$ atom dominates proton hopping, and our simulation technique allows the appropriate degree of flexibility to the internal atoms to allow proton transfer.

Variable temperature ${ }^{1} \mathrm{H}$ MAS NMR studies provide experimental evidence of proton mobility in zeolites. Room temperature spectra give a spectrum with a narrow central line and sharp spinning sidebands caused by interaction between the acidic proton and the nearby aluminum nucleus. ${ }^{29-33}$ These spinning sidebands disappear at elevated temperatures along with a broadening of the central peak, indicating that acidic protons become mobile. Experiments by Sarv et al. ${ }^{26}$ indicate proton migration in dehydrated $\mathrm{H}-\mathrm{ZSM}-5(\mathrm{Si} / \mathrm{Al}=38)$ for temperatures above $478 \mathrm{~K}$. They determined the energy barrier for proton hopping to be $11 \mathrm{kcal} / \mathrm{mol}$. A similar study by Baba et al. ${ }^{27}$ has estimated this barrier to be $4-5 \mathrm{kcal} / \mathrm{mol}$ for dehydrated $\mathrm{H}-\mathrm{ZSM}-5(\mathrm{Si} / \mathrm{Al}=21)$. It is worthwhile to note that a decrease in the $\mathrm{Si} / \mathrm{Al}$ ratio results in the increased mobility of the acidic proton, marked by a lower proton-hopping barrier. Both experimental values are considerably lower than that reported in this study; however, it is important to note that these measurements represent an average over all protons in the 


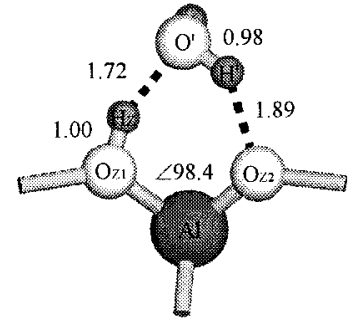

(a)

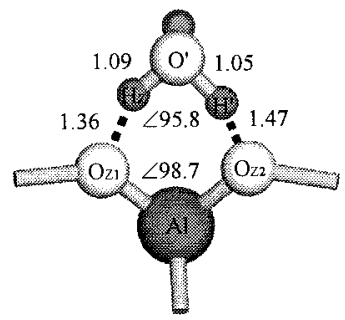

(b)

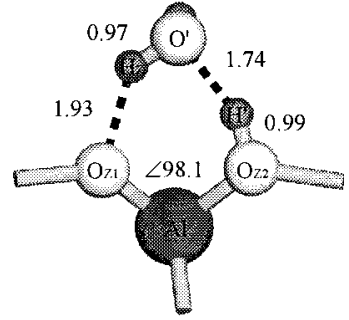

(c)

Figure 4. Adsorption complexes (a, c) and transition state (b) for water-assisted proton-hopping reaction.

TABLE 2: Selected Bond Lengths (̊̊) and Angles (deg) of Adsorbed Complexes and the Transition State for Hydrogen Exchange with Water

\begin{tabular}{|c|c|c|c|c|c|c|c|c|c|}
\hline \multirow[b]{2}{*}{ method } & \multicolumn{3}{|c|}{ (a) adsorbed complex } & \multicolumn{3}{|c|}{ (b) transition state } & \multicolumn{3}{|c|}{ (c) adsorbed complex } \\
\hline & DFT-BH\&HLYP & MP2 & DFT-B3LYP & DFT-BH\&HLYP & MP2 & DFT-BP86 & DFT-BH\&HLYP & MP2 & DFT-BP86 \\
\hline basis set & $6-31 \mathrm{G}(* *++)$ & DZVP2 & $6-31 G(* *)$ & $6-31 \mathrm{G}(* *++)$ & $6-31 \mathrm{G}(++)$ & DZP/TZP & $6-31 \mathrm{G}(* *++)$ & $6-31 \mathrm{G}(++)$ & DZP/TZP \\
\hline cluster size & $5 \mathrm{~T}$ & $3 \mathrm{~T}$ & $3 \mathrm{~T}$ & $5 \mathrm{~T}$ & $3 \mathrm{~T}$ & $5 \mathrm{~T}$ & $5 \mathrm{~T}$ & $3 \mathrm{~T}$ & $5 \mathrm{~T}$ \\
\hline reference & This work & 10 & 11 & this work & 12 & 13 & this work & 12 & 13 \\
\hline $\mathrm{O}_{\mathrm{Z}}-\mathrm{Al}-\mathrm{O}_{\mathrm{Z} 2}(\mathrm{deg})$ & 98.4 & & & 98.7 & 95.4 & 95.4 & 98.1 & 97.2 & 104.2 \\
\hline$r\left(\mathrm{O}_{\mathrm{Z} 1}-\mathrm{H}_{\mathrm{Z}}\right)(\AA)$ & 1.00 & 1.0267 & 1.039 & 1.47 & 1.36 & 1.32 & 1.93 & 1.81 & 1.71 \\
\hline$r\left(\mathrm{O}_{\mathrm{Z} 2}-\mathrm{H}^{\prime}\right)(\AA)$ & 1.89 & 1.817 & 1.886 & 1.36 & 1.36 & 1.32 & 0.99 & 1.02 & 1.05 \\
\hline$r\left(\mathrm{O}^{\prime}-\mathrm{H}_{\mathrm{Z}}\right)(\AA)$ & 1.72 & 1.611 & 1.717 & 1.47 & 1.11 & 1.146 & 0.97 & 0.99 & 1.009 \\
\hline$r\left(\mathrm{O}^{\prime}-\mathrm{H}^{\prime}\right)(\AA)$ & 0.98 & 1.0045 & 0.994 & 1.36 & 1.11 & 1.147 & 1.74 & 1.61 & 1.51 \\
\hline$r\left(\mathrm{Al}-\mathrm{O}_{\mathrm{Z} 1}\right)(\AA)$ & 1.83 & 1.934 & 1.879 & 1.76 & & & 1.69 & & \\
\hline$r\left(\mathrm{Al}-\mathrm{O}_{\mathrm{Z} 2}\right)(\AA)$ & 1.69 & & 1.776 & 1.74 & & & 1.83 & & \\
\hline$E_{\text {Ads }}(\mathrm{kcal} / \mathrm{mol})$ & -16.9 & -13.5 & -22.1 & & & & -16.0 & -22.1 & -22.0 \\
\hline$E_{\text {Act }}(\mathrm{kcal} / \mathrm{mol})$ & & & & 6.9 & 6.2 & 2.0 & & & \\
\hline$V_{\mathrm{TST}}\left(\mathrm{cm}^{-1}\right)$ & & & & $762 \mathrm{i}$ & & $659 \mathrm{i}$ & & & \\
\hline
\end{tabular}

zeolite. The present study focuses on the local structure of defect-free catalytic site under perfect vacuum. Several factors that could contribute to a discrepancy between experimental values and those presented in this paper are noted here.

Site Defects. A change in the local geometry of the catalytically active site, as in the case of a site defect, would allow more flexibility in the $\mathrm{O}-\mathrm{Al}-\mathrm{O}$ angle, lowering the activation barrier for proton mobility about the defect site. Even a small number of these sites could contribute to lowering the average or apparent activation energy measured for proton hopping.

Assisted Proton Transfer. Small gaseous species such as water may act to participate in hydrogen exchange between the $\mathrm{O}$ atoms surrounding the aluminum center. At low concentration, this would be experimentally indistinguishable from the protonhopping reaction and lower the apparent activation barrier for proton hopping.

Quantum Tunneling. Protons participating in hydrogentransfer reactions exhibit nonclassical character due to quantum mechanical tunneling. This effect is most pronounced at low temperatures, where experimental rate constants are known to deviate from Arrhenius behavior. This deviation leads to lower measured values of the apparent activation barrier.

Site defects result from either the cleavage of the oxygen bridge between $\mathrm{T}$ sites or complete removal of a $\mathrm{T}$ site from the zeolite framework proximate to the Brønsted acid site. For example, it has been proposed that dehydroxylation from steaming results in the formation of defects in the form of silanol groups. Gonzales et al. ${ }^{10}$ found that introduction of a silanol group immediately adjacent to a Brønsted acid site reduces the proton affinity by $13 \mathrm{kcal} / \mathrm{mol}$. This loss of affinity combined with greater flexibility in the zeolite framework introduced by local defects could reduce the activation barrier for proton hopping. Because of the great diversity of possible defects, we will not consider this issue further in this paper.

We will consider the role of gas-phase species in the next few sections. We will show that the presence of even an experimentally indistinguishable quantity of water dramatically influences the observed kinetics of the proton-hopping reaction. We will also discuss quantum tunneling effects in the last section, when we present a summary of overall reaction rate constants and prexponential factors for proton hopping and hydrogen exchange with $\mathrm{H}-\mathrm{ZSM}-5$.

Water-Assisted Proton Hopping. The adsorption of water to the Brønsted acid sites in zeolites is well characterized; however, its ability to mobilize acidic protons is not. ${ }^{46}$ Next we consider the role of water-assisted proton conduction in the overall mechanism for proton migration. Figure 4 presents the adsorption complexes and transition-state structure for proton exchange between water and the zeolite. Note that the 34-atom cluster shown in Figure 1 has been used for all calculations presented in this paper. For descriptive purposes, we have omitted the exterior portion of the cluster from the remaining figures to focus attention on the local chemistry at the Brønsted acid site. The structures shown in Figure $4 \mathrm{a}, \mathrm{c}$ correspond to local minima on the PES. Each complex is composed of water coordinated to the proton donor and acceptor sites by two hydrogen bonds. The adsorption energy of water to the zeolite, defined as the difference in energy between gas-phase and adsorbed water, $E_{\mathrm{Ads}}$, is $-16.9 \mathrm{kcal} / \mathrm{mol}$ for the structure shown in Figure $4 \mathrm{a}$ and $-16.0 \mathrm{kcal} / \mathrm{mol}$ for the structure shown in Figure 4c. As noted in Table 2, these values lie within the range reported in previous theoretical studies, ${ }^{11-16}-13.5$ to -22.0 $\mathrm{kcal} / \mathrm{mol}$. The range of different values reported is a consequence of the quantum chemical method and zeolite model used in each of the studies. The transition-state structure in Figure $4 \mathrm{~b}$ consists of a hydronium ion coordinated to the proton donor and acceptor sites by two hydrogen bonds. This structure constitutes a firstorder saddle point whose negative force constant is assigned to the asymmetric stretch of water: the "rocking" mode of hydrogen exchange at the transition state. The frequency associated with this rocking mode is $762 \mathrm{i} \mathrm{cm}^{-1}$. The protontransfer energy, $E_{\text {Act }}$, is $6.9 \mathrm{kcal} / \mathrm{mol}$. ZPE corrections lower 
TABLE 3: Calculated Overall Reaction Rate Constants for the Dry and Water-Assisted Proton-Hopping Reactions

\begin{tabular}{lcccccc}
\hline & \multicolumn{2}{c}{ dry proton hopping } & & \multicolumn{3}{c}{ water-assisted proton hopping } \\
\cline { 2 - 3 } \cline { 5 - 6 }$T(\mathrm{~K})$ & $k_{\mathrm{o}}\left(\mathrm{s}^{-1}\right)$ & $k\left(\mathrm{~s}^{-1}\right)$ & & $k_{\mathrm{o}}\left(\mathrm{s}^{-1}\right)$ & $k\left(\mathrm{~s}^{-1}\right)$ & $k_{\mathrm{H}_{2} \mathrm{O}} / k_{\mathrm{DRY}}$ \\
\hline 200 & $4.16 \mathrm{E}+12$ & $1.12 \mathrm{E}-18$ & & $3.43 \mathrm{E}+12$ & $2.05 \mathrm{E}+08$ & $1.83 \mathrm{E}+26$ \\
298.15 & $6.15 \mathrm{E}+12$ & $1.91 \mathrm{E}-08$ & & $4.08 \mathrm{E}+12$ & $6.00 \mathrm{E}+09$ & $3.13 \mathrm{E}+17$ \\
400 & $8.07 \mathrm{E}+12$ & $4.18 \mathrm{E}-03$ & & $4.39 \mathrm{E}+12$ & $3.39 \mathrm{E}+10$ & $8.11 \mathrm{E}+12$ \\
500 & $9.80 \mathrm{E}+12$ & $5.80 \mathrm{E}+00$ & & $4.53 \mathrm{E}+12$ & $9.25 \mathrm{E}+10$ & $1.60 \mathrm{E}+10$ \\
600 & $1.14 \mathrm{E}+13$ & $7.35 \mathrm{E}+02$ & & $4.61 \mathrm{E}+12$ & $1.80 \mathrm{E}+11$ & $2.45 \mathrm{E}+08$ \\
700 & $1.29 \mathrm{E}+13$ & $2.37 \mathrm{E}+04$ & & $4.67 \mathrm{E}+12$ & $2.90 \mathrm{E}+11$ & $1.22 \mathrm{E}+07$ \\
800 & $1.43 \mathrm{E}+13$ & $3.25 \mathrm{E}+05$ & & $4.73 \mathrm{E}+12$ & $4.16 \mathrm{E}+11$ & $1.28 \mathrm{E}+06$ \\
900 & $1.56 \mathrm{E}+13$ & $2.51 \mathrm{E}+06$ & & $4.81 \mathrm{E}+12$ & $5.54 \mathrm{E}+11$ & $2.21 \mathrm{E}+05$ \\
1000 & $1.68 \mathrm{E}+13$ & $1.29 \mathrm{E}+07$ & & $4.88 \mathrm{E}+12$ & $6.99 \mathrm{E}+11$ & $5.39 \mathrm{E}+04$
\end{tabular}

this barrier by $3 \mathrm{kcal} / \mathrm{mol}$. Selected bond lengths and angles for hydrogen exchange between water and zeolite are listed in Table 2.

Previous theoretical studies support the presence of a hydronium ion as a transition state for the hydrogen exchange reaction. Zygmunt et al. ${ }^{14}$ have modeled hydrogen exchange of water with ZSM-5 using a symmetric, relaxed 3T atom zeolite model. Using MP2 methods, they computed the proton-transfer energy to be $6.2 \mathrm{kcal} / \mathrm{mol}$. This is in good agreement with our results prior to ZPE correction. Krossner et al. ${ }^{15,16}$ have reported an activation barrier of $2.0 \mathrm{kcal} / \mathrm{mol}$ based on DFT calculations carried out with the BP86 functional for an asymmetric, relaxed 5T cluster. Again, a major difference between the present and previous studies is the allowed flexibility of the cluster. Our calculations predict a value of $98.7^{\circ}$ for the $\mathrm{O}-\mathrm{Al}-\mathrm{O}$ angle at the transition state, compared to 96.8 and $95.4^{\circ}$ for Zygmunt et al. and Krossner et al., respectively. Table 2 compares the results of our study with those reported previously.

The overall reaction rate constants and frequency factors for dry and water-assisted proton hopping in the model zeolite were computed over a range of temperatures and are included in Table 3. The large difference in rate between the two mechanisms, on the order of $10^{26}$ at low temperature and $10^{4}$ at high temperature, emphasizes the large impact of even a small amount of water on the mobility of acidic protons about the Brønsted acid site. To illustrate this further, we consider the overall rate of proton hopping, $r_{\mathrm{HOP}}$, to consist of a linear combination of rates of dry and water-assisted proton hopping, denoted $r_{\mathrm{DRY}}$ and $r_{\mathrm{H}_{2} \mathrm{O}}$, respectively

$$
r_{\mathrm{HOP}}=(1-\theta) r_{\mathrm{DRY}}+\theta r_{\mathrm{H}_{2} \mathrm{O}}
$$

where $\theta$ is the fractional coverage of water over the total number of catalytically active sites defined by the Langmuir isotherm

$$
\theta=\frac{K_{\mathrm{H}_{2} \mathrm{O}} P_{\mathrm{H}_{2} \mathrm{O}}}{1+K_{\mathrm{H}_{2} \mathrm{O}} P_{\mathrm{H}_{2} \mathrm{O}}}
$$

In eq $11, P_{\mathrm{H}_{2} \mathrm{O}}$ is the partial pressure of water in atmospheres and $K_{\mathrm{H}_{2} \mathrm{O}}$ is the equilibrium constant for water adsorbed to the Brønsted acid site computed using the formula

$$
K_{\mathrm{H}_{2} \mathrm{O}}=\frac{q_{\mathrm{H}_{2} \mathrm{O}-\mathrm{H}^{+} \mathrm{OZ}-\text {,vib }}}{q_{\mathrm{H}_{2} \mathrm{O}, \text { trans }} q_{\mathrm{H}_{2} \mathrm{O}, \mathrm{rot}} q_{\mathrm{H}_{2} \mathrm{O}, \mathrm{vib}} q_{\mathrm{H}^{+} \mathrm{OZ}^{-}, \mathrm{vib}}} \mathrm{e}^{-E_{\mathrm{Ads}} / R T}
$$

We have assumed an equilibrium distribution of water because the time scale associated with the diffusion of water in a unit cell is 2 orders of magnitude smaller than the characteristic time for proton hopping.

If we fix the total moles of zeolite in a system of constant volume, as in the case of a sealed ampule used in a typical

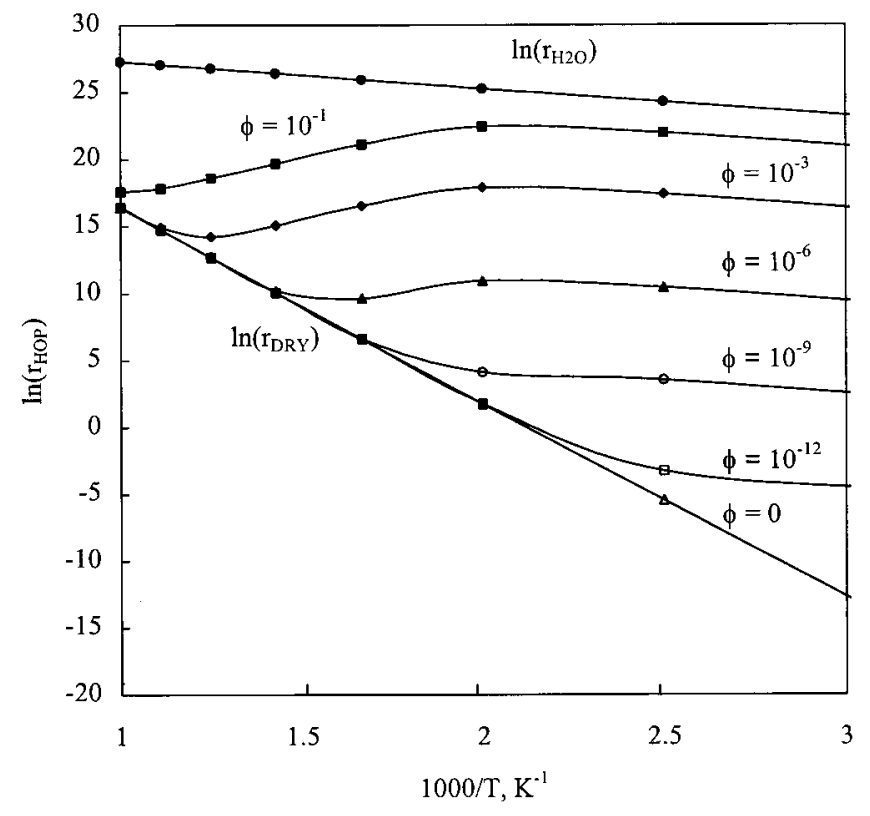

Figure 5. Overall rate of proton hopping versus temperature for dry and water-assisted proton-hopping reaction.

NMR experiment, we can compare the rates of proton hopping for different amounts of water over a range of temperatures. Figure 5 shows the overall rate of proton hopping versus inverse temperature for a system containing $0.1 \mathrm{~g}$ of zeolite $(\mathrm{Si} / \mathrm{Al}=$ 16) and $1 \mathrm{~cm}^{3}$ of vapor volume. Each line corresponds to a different molar ratio of water to zeolite, $\phi=N_{\mathrm{H}_{2} \mathrm{O}} / N_{\mathrm{ZH}}$. In the high molar ratio limit, $\phi=1$, the system behaves as though all sites are saturated by water at low temperature, and hence the rate of proton mobility is equal to that of water-assisted proton transfer. In the low molar ratio limit, $\phi=0$, the system behaves as though no sites contain adsorbed water at any temperature and the rate of proton migration is that characteristic of proton hopping in the absence of $\mathrm{H}_{2} \mathrm{O}$. The more interesting physical cases lie between these extremes, where a vanishingly small amount of water is present in the system over a range of temperatures.

Note that for temperatures $\leq 500 \mathrm{~K}$, the activation barrier for proton migration, taken as the slope of $\ln \left(r_{\mathrm{HOP}}\right)$ versus $1 / T$, resembles that of water-assisted proton transfer for all nonzero values of $\phi$. This corresponds to the physical case where some of the water molecules present in the system are adsorbed on Brønsted acid sites and assist the proton-hopping reaction. Because of the large difference in magnitude of the two rates, water-assisted proton hopping dominates the rate. Even as little as 1 ppm of water per acidic proton, an amount indistinguishable by most experimental means, will reduce the apparent activation energy from $28 \mathrm{kcal} / \mathrm{mol}$ for completely dry $\mathrm{H}-\mathrm{ZSM}-5$ to $\sim 4$ $\mathrm{kcal} / \mathrm{mol}$.

Over the intermediate range of temperatures, 600-800 K, water begins to desorb from the acid sites and the rate of proton hopping diminishes. Beyond $800 \mathrm{~K}$, almost all water in the system resides in the gas phase, hence the rate of proton hopping equals that of dry proton hopping. The temperature dependence of the rate in the region above $600 \mathrm{~K}$ is nonlinear due to a shift in the water-zeolite equilibrium. The nonlinear behavior, if measured judiciously and plotted over this temperature regime, would be interpreted as a negative activation barrier for proton hopping. However, if one assumed that the zeolite sample was completely dry and considered the first-order rate dependence over the entire range of temperatures (e.g., refs 29 and 30), this 


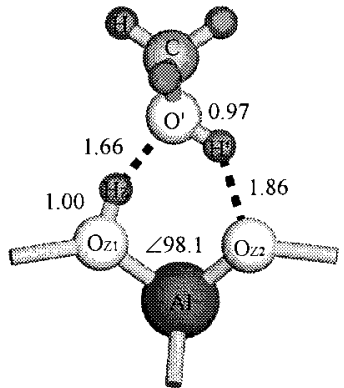

(a)

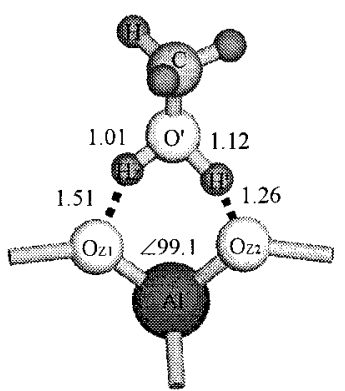

(b)

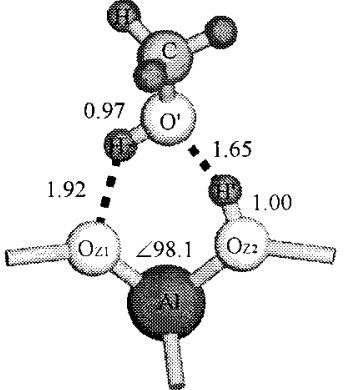

(c)

Figure 6. Adsorption complexes $(\mathrm{a}, \mathrm{c})$ and transition state (b) for hydrogen exchange with methanol.

TABLE 4: Selected Bond Lengths (Å) and Angles (degrees) of Adsorbed Complexes and the Transition State for Hydrogen Exchange with Methanol

\begin{tabular}{|c|c|c|c|c|c|c|c|c|c|}
\hline \multirow[b]{2}{*}{ method } & \multicolumn{3}{|c|}{ (a) adsorbed complex } & \multicolumn{3}{|c|}{ (b) transition state } & \multicolumn{3}{|c|}{ (c) adsorbed complex } \\
\hline & DFT-BH\&HLYP & DFT-BLYP & DFT-B3LYP & DFT-BH\&HLYP & DFT-BP86 & MP2 & DFT-BH\&HLYP & DFT-BP86 & MP2 \\
\hline basis set & $6-31 \mathrm{G}(* *++)$ & DZVP2 & $6-31 \mathrm{G}(* *)$ & $6-31 \mathrm{G}(* *++)$ & DZPV & $\mathrm{DZP} / \mathrm{TZP}$ & $6-31 \mathrm{G}(* *++)$ & DZPV & $\mathrm{DZP} / \mathrm{TZP}$ \\
\hline cluster size & $5 \mathrm{~T}$ & $3 \mathrm{~T}$ & $3 \mathrm{~T}$ & $5 \mathrm{~T}$ & $3 \mathrm{~T}$ & $5 \mathrm{~T}$ & $5 \mathrm{~T}$ & $3 \mathrm{~T}$ & $5 \mathrm{~T}$ \\
\hline reference & this work & 10 & 11 & this work & 16 & 18 & this work & 16 & 18 \\
\hline $\mathrm{O}_{\mathrm{Z} 1}-\mathrm{Al}-\mathrm{O}_{\mathrm{Z} 2}(\mathrm{deg})$ & 98.1 & & 90.5 & 99.1 & 94.98 & 96.8 & 98.1 & 97.19 & 98.0 \\
\hline$r\left(\mathrm{O}_{\mathrm{Z} 1}-\mathrm{H}_{\mathrm{Z}}\right)(\AA)$ & 1.00 & 1.035 & 1.049 & 1.26 & 1.348 & 1.366 & 1.92 & 1.786 & 1.762 \\
\hline$r\left(\mathrm{O}_{\mathrm{Z} 2}-\mathrm{H}^{\prime}\right)(\AA)$ & 1.86 & 1.837 & & 1.51 & 1.348 & 1.366 & 1.00 & 1.052 & 1.049 \\
\hline$r\left(\mathrm{O}^{\prime}-\mathrm{H}_{\mathrm{Z}}\right)(\AA)$ & 1.66 & 1.569 & 1.482 & 1.01 & 1.123 & 1.086 & 0.97 & 1.005 & 0.993 \\
\hline$r\left(\mathrm{O}^{\prime}-\mathrm{H}^{\prime}\right)(\AA)$ & 0.97 & 1.001 & 0.967 & 1.12 & 1.123 & 1.086 & 1.65 & 1.527 & 1.453 \\
\hline$r\left(\mathrm{C}-\mathrm{O}^{\prime}\right)(\AA)$ & 1.41 & 1.46 & 1.432 & 1.42 & 1.464 & 1.444 & 1.42 & 1.449 & 1.431 \\
\hline$r\left(\mathrm{Al}-\mathrm{O}_{\mathrm{Z} 1}\right)(\AA)$ & 1.83 & 1.945 & 1.88 & 1.73 & 1.864 & 1.808 & 1.70 & 1.788 & 1.728 \\
\hline$r\left(\mathrm{Al}-\mathrm{O}_{\mathrm{Z} 2}\right)(\AA)$ & 1.69 & & 1.779 & 1.76 & 1.863 & 1.808 & 1.82 & 1.926 & 1.905 \\
\hline$E_{\text {Ads }}(\mathrm{kcal} / \mathrm{mol})$ & -17.1 & -16.7 & -21.0 & & & & -15.9 & -17.5 & -20.9 \\
\hline$E_{\text {Act }}(\mathrm{kcal} / \mathrm{mol})$ & & & & 6.5 & 2.6 & 0 & & & \\
\hline$V_{\mathrm{TST}}\left(\mathrm{cm}^{-1}\right)$ & & & & $397 \mathrm{i}$ & $3561 \mathrm{i}$ & & & & \\
\hline
\end{tabular}

would lead to the result of a measured activation energy between that of dry proton hopping and that of water-assisted proton transfer.

We have shown that the presence of an adsorbed water molecule at the Brønsted acid site can dramatically influence the kinetics of proton hopping in $\mathrm{H}-\mathrm{ZSM}-5$. We suggest that this is an important reason for the observed low activation barriers for proton hopping in ZSM-5. We now broaden the scope of our study to investigate the influence of other activating species on the mobility, and hence reactivity, of acidic protons.

Hydrogen Exchange with $\mathbf{R}-\mathbf{O H}$. In the last section we examined the impact of adsorbed water on the kinetics of proton mobility about the Al tetrahedron. On the basis of the similar hydroxyl moiety in methanol and ethanol, we now consider the proton conduction properties of the general assisted protonhopping reaction (9), where $\mathrm{RO}-\mathrm{H}$ represents the series of simple alcohols $\mathrm{H}_{2} \mathrm{O}, \mathrm{CH}_{3} \mathrm{OH}$, and $\mathrm{CH}_{3} \mathrm{CH}_{2} \mathrm{OH}$.

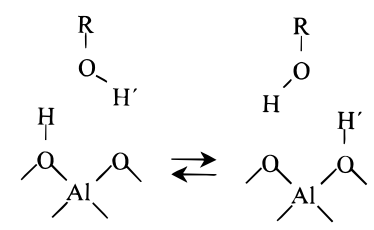

The adsorption complexes and transition-state structure for hydrogen exchange between methanol and the zeolite are shown in Figure 6. As in the case of water-assisted proton hopping, each structure consists of methanol coordinated to the proton donor and acceptor sites through the protons involved in transfer. The adsorption energy of methanol to the zeolite, $E_{\text {Ads }}$, is -17.1 $\mathrm{kcal} / \mathrm{mol}$ for the structure shown in Figure $6 \mathrm{a}$ and $-15.9 \mathrm{kcal} /$ mol for the structure shown in Figure $6 \mathrm{c}$, consistent with previous studies. ${ }^{12,13,17-20}$ The transition-state structure in Figure $6 \mathrm{~b}$ is composed of a methoxonium ion coordinated to the zeolite framework through the proton donor and proton acceptor $\mathrm{O}$ atoms. It is a first-order saddle point on the PES with one negative force constant assigned to the asymmetric stretch of methanol and hydrogen exchange. The imaginary frequency associated with this rocking mode is $397 \mathrm{i} \mathrm{cm}^{-1}$. The computed activation energy is $6.5 \mathrm{kcal} / \mathrm{mol}$. ZPE corrections reduce the activation barrier by $2.6 \mathrm{kcal} / \mathrm{mol}$. Selected bond lengths and angles for hydrogen exchange between methanol and zeolite are given in Table 4 .

Other theoretical studies of methanol in zeolites have concluded that the methoxonium ion is a transition state for hydrogen exchange. DFT-BP86 calculations by Blaszkowski et al. ${ }^{18}$ computed the activation energy to be $2.6 \mathrm{kcal} / \mathrm{mol}$ for a symmetric, fully relaxed $3 \mathrm{~T}$ zeolite model. Bates et al. ${ }^{19}$ reported $1.6 \mathrm{kcal} / \mathrm{mol}$ for proton transfer in a similar cluster using MP2 methods. Haase et al. ${ }^{20}$ determined that the barrier height was negligible for MP2 calculations on an asymmetric, relaxed 5T cluster model. The lower activation energies in both of these studies can be ascribed to the use of unconstrained clusters, which allow full relaxation of the zeolite framework to stabilize the transition state. Our calculations predict a value of $99.1^{\circ}$ for the $\mathrm{O}-\mathrm{Al}-\mathrm{O}$ angle at the transition state, compared to 95.0, 96.0, and $96.8^{\circ}$ for Blaszkowski et al., Bates et al., and Haase et al., respectively. A detailed comparison of the present work to the previous studies is included in Table 4.

Figure 7 illustrates the different adsorption complexes for proton exchange between ethanol and the zeolite. Parts a and $\mathrm{c}$ of Figure 7 show ethanol coordinated to the acidic proton by two hydrogen bonds. The calculated adsorption energies for the two structures are -14.9 and $-16.4 \mathrm{kcal} / \mathrm{mol}$, respectively. The 




(a)

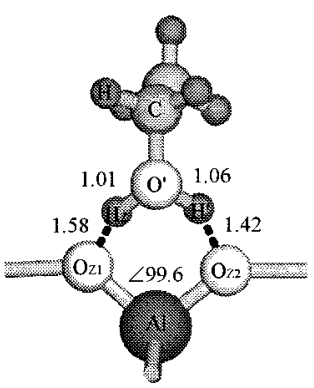

(b)

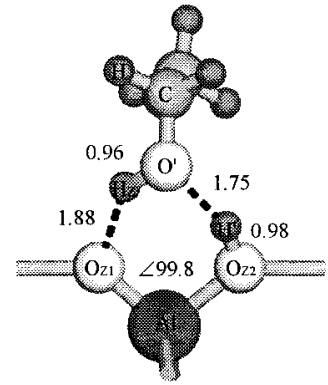

(c)

Figure 7. Adsorption complexes (a, c) and transition state (b) for hydrogen exchange with ethanol.

TABLE 5: Selected Bond Lengths $(\AA)$ and Angles (deg) of Adsorbed Complexes and the Transition State for Hydrogen Exchange with Ethanol

\begin{tabular}{llll}
\hline & (a) adsorbed complex & (b) transition state & (c) adsorbed complex \\
\hline method & DFT-BH\&HLYP & DFT-BH\&HLYP & DFT-BH\&HLYP \\
basis set & $6-31 \mathrm{G}(* *++)$ & $6-31 \mathrm{G}(* *++)$ & $6-31 \mathrm{G}(* *++)$ \\
cluster size & $\mathrm{ST}$ & $5 \mathrm{~T}$ & $5 \mathrm{~T}$ \\
$\mathrm{O}_{\mathrm{Zl}}-\mathrm{Al}-\mathrm{O}_{\mathrm{Z} 2}(\mathrm{deg})$ & 99.8 & 99.6 & 98.1 \\
$r\left(\mathrm{O}_{\mathrm{Z1}}-\mathrm{H}_{\mathrm{Z}}\right)(\AA)$ & 0.98 & 1.42 & 1.93 \\
$r\left(\mathrm{O}_{\mathrm{Z} 2}-\mathrm{H}^{\prime}\right)(\AA)$ & 1.88 & 1.58 & 1.00 \\
$r\left(\mathrm{O}^{\prime}-\mathrm{H}_{\mathrm{Z}}\right)(\AA)$ & 1.75 & 1.01 & 0.97 \\
$r\left(\mathrm{O}^{\prime}-\mathrm{H}^{\prime}\right)(\AA)$ & 0.96 & 1.06 & 1.62 \\
$r\left(\mathrm{C}-\mathrm{O}^{\prime}\right)(\AA)$ & 1.40 & 1.44 & 1.42 \\
$r\left(\mathrm{Al}-\mathrm{O}_{\mathrm{Zl}}\right)(\AA)$ & 1.83 & 1.73 & 1.70 \\
$r\left(\mathrm{Al}-\mathrm{O}_{\mathrm{Z} 2}\right)(\AA)$ & 1.68 & 1.75 & 1.82 \\
$E_{\mathrm{Ads}}(\mathrm{kcal} / \mathrm{mol})$ & -14.9 & 7.5 & -16.4 \\
$E_{\mathrm{Act}}(\mathrm{kcal} / \mathrm{mol})$ & & 7.5
\end{tabular}

transition-state structure in Figure $7 \mathrm{~b}$ consists of ethoxonium ion coordinated to the zeolite framework by two hydrogen bonds. The activation energy of this complex is $7.5 \mathrm{kcal} / \mathrm{mol}$. Selected bond lengths and angles for hydrogen exchange between ethanol and zeolite are provided in Table 5.

Hard-soft acid-base theory (HSAB) predicts that soft acids will prefer soft bases and hard acids will prefer hard bases. A measure of softness of an acid or base is its polarizability. From a physical standpoint, water, methanol, and ethanol are polarizable molecules. This is illustrated by the index of refraction exhibited by these compounds: 1.333, 1.3288, and 1.3611, respectively. It is evident that to a first approximation the activation energy for hydrogen exchange with $\mathrm{R}-\mathrm{OH}$ increases with an increase in polarizability, denoted by a larger index of refraction of the species $\mathrm{RO}-\mathrm{H}$. We propose that since the proton is a hard acid, it prefers a hard base. Hence the more polarizable the base becomes (as indicated by a higher refractive index), in the order $\mathrm{CH}_{3} \mathrm{OH}<\mathrm{H}_{2} \mathrm{O}<\mathrm{CH}_{3} \mathrm{CH}_{2} \mathrm{OH}$, the higher the activation barrier for assisted proton transfer about the Brønsted acid site.

Hydrogen Exchange with $\mathbf{R}-\mathbf{H}$. The utility of zeolites in cracking and other hydrocarbon re-forming processes motivates discussion of the mobility of acidic protons due to hydrogen exchange with participating reactant and product species. This involves the series dihydrogen, methane, and higher order hydrocarbons, all of which are rich in hydrogen and have been shown to participate in exchange with zeolites at various temperatures. The reaction proceeds in the following fashion:

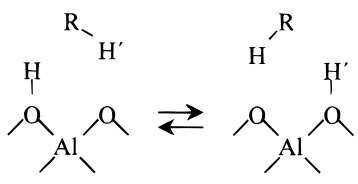

In eq $10 \mathrm{R}-\mathrm{H}$ denotes the reacting species $\left(\mathrm{R}=\mathrm{H}, \mathrm{CH}_{3}, \mathrm{C}_{2} \mathrm{H}_{5}\right.$, $\mathrm{C}_{3} \mathrm{H}_{7}, \mathrm{C}_{6} \mathrm{H}_{5}$ ).
Figure 8 portrays the hydrogen exchange reaction between dihydrogen and the zeolite cluster. Parts a and $\mathrm{c}$ of Figure 8 show free, dissociated molecular hydrogen in proximity of the Brønsted acid site. No energy minima were found for dihydrogen adsorbed to either acid site of the zeolite cluster. Figure $8 b$ shows the activated complex of dihydrogen with the acidic proton. This corresponds to a saddle point in the PES with one negative force constant associated with proton transfer. The imaginary frequency attributed to the transition state is $1679 \mathrm{i}$ $\mathrm{cm}^{-1}$. The activation energy, defined as the difference in energy between the activated complex and reactants, $E_{\mathrm{Act}}$, is $31.9 \mathrm{kcal} /$ mol. The ZPE correction raises the activation barrier by 1.5 $\mathrm{kcal} / \mathrm{mol}$. Selected bond lengths and angles for the hydrogen exchange reaction with dihydrogen are listed Table 6 along with a comparison with previous related efforts.

Deuterium exchange reactions on $\mathrm{H}-\mathrm{ZSM}-5$ have been performed by Biscardi et al. ${ }^{47}$ They found that $\mathrm{D}_{2}$ dissociates and exchanges with surface hydrogen atoms between 600 and $1000 \mathrm{~K}$, and then $\mathrm{H}$ desorbs from the surface as $\mathrm{HD}$ and $\mathrm{H}_{2}$. The prexponential factor and activation energy were computed by fitting the HD desorption peak. These values are $4.16 \times 10^{8}$ $\mathrm{cm}^{3} /(\mathrm{Al}$ site $\cdot \mathrm{s})$ and $21 \mathrm{kcal} / \mathrm{mol}$, respectively. Our computed barrier, corrected for $\mathrm{ZPE}$, is $12 \mathrm{kcal} / \mathrm{mol}$ higher than the experimental value. In view of this result, we make reference to arguments made previously in the paper. The experimental value provides an average view of hydrogen exchange with all available hydrogen on the zeolite surface. This includes defect sites with lower proton affinity, hence more ready exchange.

Figure 9 shows proton exchange reaction between methane and $\mathrm{H}-\mathrm{ZSM}-5$. Parts and and $\mathrm{c}$ of Figure 9 depict free methane in proximity of the Brønsted acid site. No stable structure was found for the adsorption complex of methane with the Brønsted acid site. Figure $9 \mathrm{~b}$ shows the activated complex of methane with the zeolite cluster. This consists of a carbonium species, $\mathrm{CH}_{5}{ }^{+}$, associated with the proton donor and acceptor sites 




(a)

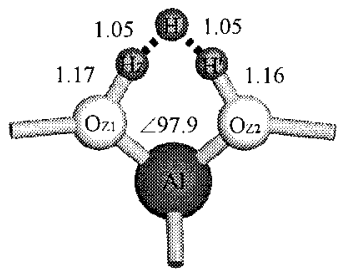

(b)

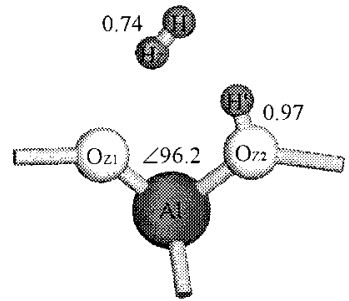

(c)

Figure 8. Dissociated species (a, c) and activated complex (b) for hydrogen exchange with dihydrogen.



(a)

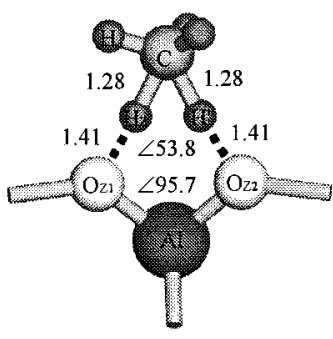

(b)

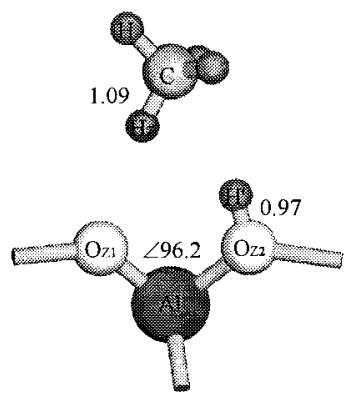

(c)

Figure 9. Dissociated species (a, c) and activated complex (b) for hydrogen exchange with methane.

TABLE 6: Selected Bond Lengths (̊̊) and Angles (deg) of Dissociated Species and the Activated Complex for Hydrogen Exchange with Dihydrogen

\begin{tabular}{|c|c|c|c|c|}
\hline \multirow[b]{2}{*}{ method } & \multirow{2}{*}{$\frac{\text { (a) dissociated species }}{\text { DFT-BH\&HLYP }}$} & \multicolumn{2}{|c|}{ (b) activated complex } & \multirow{2}{*}{$\frac{\text { (c) dissociated species }}{\text { DFT-BH\&HLYP }}$} \\
\hline & & DFT-BH\&HLYP & MP2 & \\
\hline basis set & $6-31 \mathrm{G}(* *++)$ & $6-31 \mathrm{G}(* *++)$ & $6-31 \mathrm{G}(* *++)$ & $6-31 \mathrm{G}(* *++)$ \\
\hline cluster size & $5 \mathrm{~T}$ & $5 \mathrm{~T}$ & IT & $5 \mathrm{~T}$ \\
\hline reference & this work & this work & 20 & this work \\
\hline $\mathrm{O}_{\mathrm{Z}}-\mathrm{Al}-\mathrm{O}_{\mathrm{Z} 2}(\mathrm{deg})$ & 96.9 & 97.9 & 90.1 & 96.1 \\
\hline$r\left(\mathrm{O}_{\mathrm{Z} 1}-\mathrm{H}_{\mathrm{Z}}\right)(\AA)$ & 0.97 & 1.16 & 1.09 & \\
\hline$r\left(\mathrm{O}_{\mathrm{Z2} 2}-\mathrm{H}^{\prime}\right)(\AA)$ & & 1.17 & 1.09 & 0.97 \\
\hline$r\left(\mathrm{H}-\mathrm{H}_{\mathrm{Z}}\right)(\AA)$ & & 1.05 & 1.22 & 0.74 \\
\hline$r\left(\mathrm{H}-\mathrm{H}^{\prime}\right)(\AA)$ & 0.74 & 1.05 & 1.22 & \\
\hline$r\left(\mathrm{Al}-\mathrm{O}_{\mathrm{Z} 1}\right)(\AA)$ & 1.86 & 1.77 & 1.88 & 1.68 \\
\hline$r\left(\mathrm{Al}-\mathrm{O}_{\mathrm{Z} 2}\right)(\AA)$ & 1.68 & 1.76 & 1.88 & 1.86 \\
\hline$E_{\text {Act }}(\mathrm{kcal} / \mathrm{mol})$ & & 31.9 & 32.0 & \\
\hline$V_{\mathrm{TST}}\left(\mathrm{cm}^{-1}\right)$ & & $1679 \mathrm{i}$ & & \\
\hline
\end{tabular}

through the two protons involved in the exchange. The transition-state structure for hydrogen exchange corresponds to a saddle point on the potential energy surface with one negative force constant assigned to the rocking mode of carbonium and proton exchange. The imaginary frequency of this mode is $1435 \mathrm{i}$ $\mathrm{cm}^{-1}$. The calculated activation barrier, uncorrected for zeropoint energy, is $40.7 \mathrm{kcal} / \mathrm{mol}$. ZPE corrections reduce the observed barrier by $2.3 \mathrm{kcal} / \mathrm{mol}$. Experimental studies by Larson et al. ${ }^{48}$ determined the activation energy for deuterium exchange to be $33.4 \mathrm{kcal} / \mathrm{mol}$ for exchange of $\mathrm{CD}_{4}$ with $\mathrm{H}-\mathrm{ZSM}-5$. This result lies within $4 \mathrm{kcal} / \mathrm{mol}$ of our ZPE corrected barrier. Selected bond lengths and angles for minimum energy and transition structures are provided in Table 7, along with a comparison with previous related studies.

Parts a and $\mathrm{c}$ of Figure 10 depict free ethane in proximity of the Brønsted acid site. No stable structure was found for the adsorption complex of ethane with the Brønsted acid site. Figure $10 \mathrm{~b}$ shows the activated complex of ethane with the zeolite cluster. This consists of one carbon of ethane associated with the proton donor and acceptor sites through the two protons involved in the exchange. The transition-state structure corresponds to a saddle point in the potential energy surface with one negative force constant assigned to the rocking mode of proton exchange. The frequency associated with this mode is $1147 \mathrm{i} \mathrm{cm}^{-1}$. The computed activation energy for hydrogen exchange is $40.0 \mathrm{kcal} / \mathrm{mol}$. ZPE corrections reduce the observed barrier by $1.7 \mathrm{kcal} / \mathrm{mol}$. Selected bond lengths and angles for hydrogen exchange between ethane and zeolite and a comparison with previous related efforts are provided in Table 8.

Unlike methane and ethane, propane provides the opportunity to probe two chemically different carbon environments within the same hydrocarbon molecule. These include the methyl carbon $\left(\mathrm{C}^{\prime}\right)$ and methylene carbon $\left(\mathrm{C}^{\prime \prime}\right)$, as shown below

$$
\begin{aligned}
& \begin{array}{cccc}
\mathrm{H} & \mathrm{H} & \mathrm{H} \\
\mathrm{H}-\mathrm{C}^{\prime} & -\mathrm{C}^{-} & -\mathrm{C}^{-} & -\mathrm{H} \\
\mathrm{H} & \mathrm{H} & \mathrm{H} \\
\mathrm{H} & \mathrm{H} & \mathrm{H}
\end{array}
\end{aligned}
$$

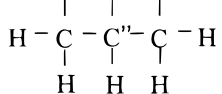

$$
\begin{aligned}
& \text { Methyl group of propane (C') Methylene group of propane (C') }
\end{aligned}
$$

Figure 11 shows the proton exchange reaction between a methyl group of propane and the zeolite. Parts a and c of Figure 11 depict free propane in proximity of the Brønsted acid site. No stable structure was found for the adsorption complex of 


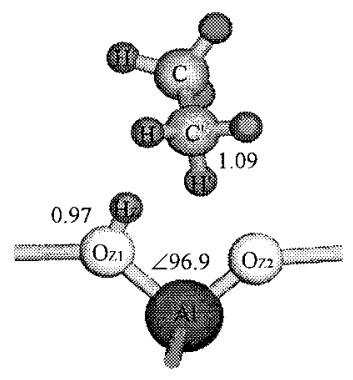

(a)

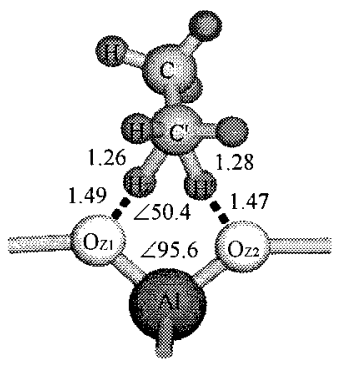

(b)

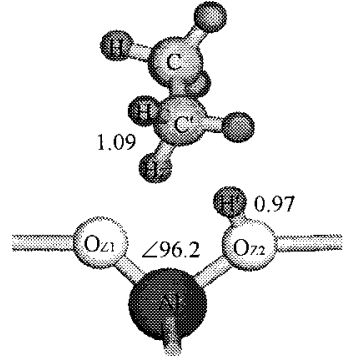

(c)

Figure 10. Dissociated species (a, c) and activated complex (b) for hydrogen exchange with ethane.

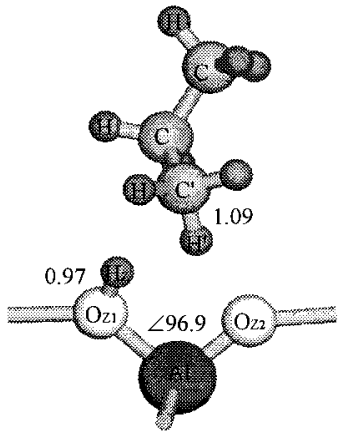

(a)

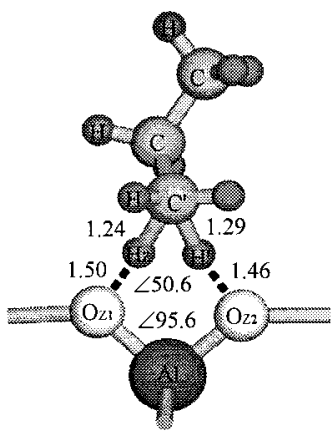

(b)

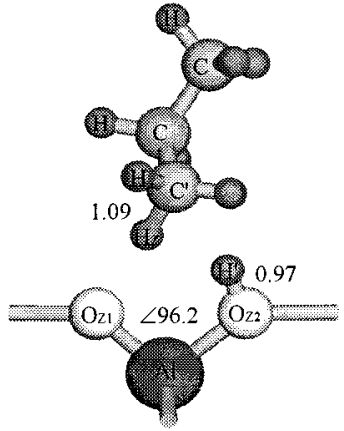

(c)

Figure 11. Dissociated species (a, c) and activated complex (b) for hydrogen exchange with methyl group of propane.

TABLE 7: Selected Bond Lengths $(\AA)$ and Angles (degrees) of Dissociated Species and the Activated Complex for Hydrogen Exchange with Methane

\begin{tabular}{|c|c|c|c|c|c|}
\hline \multirow[b]{2}{*}{ method } & \multirow{2}{*}{$\frac{\text { (a) dissociated species }}{\text { DFT-BH\&HLYP }}$} & \multicolumn{3}{|c|}{ (b) activated complex } & \multirow{2}{*}{$\frac{\text { (c) dissociated species }}{\text { DFT-BH\&HLYP }}$} \\
\hline & & DFT-BH\&HLYP & DFT-BP86 & DFT-BH\&HLYP & \\
\hline basis set & $6-31 \mathrm{G}(* *++)$ & $6-31 \mathrm{G}(* *++)$ & $6-31 \mathrm{G}(* *)$ & $6-31 \mathrm{G}(* *++)$ & $6-31 \mathrm{G}(* *++)$ \\
\hline cluster size & $5 \mathrm{~T}$ & $5 \mathrm{~T}$ & $3 \mathrm{~T}$ & $3 \mathrm{~T}$ & $5 \mathrm{~T}$ \\
\hline reference & this work & this work & 22 & 23 & this work \\
\hline $\mathrm{O}_{\mathrm{Z} 1}-\mathrm{A} 1-\mathrm{O}_{\mathrm{Z} 2}(\mathrm{deg})$ & 96.9 & 95.7 & 92.3 & & 96.1 \\
\hline$r\left(\mathrm{O}_{\mathrm{Z} 1}-\mathrm{H}_{\mathrm{Z}}\right)(\AA)$ & 0.97 & 1.41 & 1.399 & 1.322 & \\
\hline$r\left(\mathrm{O}_{\mathrm{Z} 2}-\mathrm{H}^{\prime}\right)(\AA)$ & & 1.41 & 1.399 & 1.322 & 0.97 \\
\hline$r\left(\mathrm{C}-\mathrm{H}_{\mathrm{Z}}\right)(\AA)$ & & 1.28 & 1.282 & 1.322 & 1.09 \\
\hline$r\left(\mathrm{C}-\mathrm{H}^{\prime}\right)(\AA)$ & 1.09 & 1.28 & 1.282 & 1.322 & \\
\hline$r\left(\mathrm{Al}-\mathrm{O}_{\mathrm{Z} 1}\right)(\AA)$ & 1.86 & 1.75 & 1.801 & & 1.68 \\
\hline$r\left(\mathrm{Al}-\mathrm{O}_{\mathrm{Z} 2}\right)(\AA)$ & 1.68 & 1.75 & 1.801 & & 1.86 \\
\hline$E_{\text {Act }}(\mathrm{kcal} / \mathrm{mol})$ & & 40.7 & 31.3 & 37.7 & \\
\hline$V_{\mathrm{TST}}\left(\mathrm{cm}^{-1}\right)$ & & $1435 \mathrm{i}$ & $1128 \mathrm{i}$ & $1832 \mathrm{i}$ & \\
\hline
\end{tabular}

TABLE 8: Selected Bond Lengths (̊̊) and Angles (deg) of Dissociated Species and the Activated Complex for Hydrogen Exchange with Ethane

\begin{tabular}{|c|c|c|c|c|}
\hline \multirow[b]{2}{*}{ method } & \multirow{2}{*}{$\begin{array}{c}\text { (a) dissociated species } \\
\text { DFT-BH\&HLYP }\end{array}$} & \multicolumn{2}{|c|}{ (b) activated complex } & \multirow{2}{*}{$\begin{array}{c}\text { (c) dissociated species } \\
\text { DFT-BH\&HLYP }\end{array}$} \\
\hline & & DFT-BH\&HLYP & DFT-BP86 & \\
\hline basis set & $6-31 \mathrm{G}(* *++)$ & $6-31 \mathrm{G}(* *++)$ & $6-31 \mathrm{G}(* *)$ & $6-31 \mathrm{G}(* *++)$ \\
\hline cluster size & $5 \mathrm{~T}$ & $5 \mathrm{~T}$ & $3 \mathrm{~T}$ & $5 \mathrm{~T}$ \\
\hline reference & this work & this work & 21 & this work \\
\hline $\mathrm{O}_{\mathrm{Zl}}-\mathrm{Al}-\mathrm{O}_{\mathrm{Z} 2}(\mathrm{deg})$ & 96.9 & 95.6 & 88.8 & 96.1 \\
\hline$r\left(\mathrm{O}_{\mathrm{Z} 1}-\mathrm{H}_{\mathrm{Z}}\right)(\AA)$ & 0.97 & 1.49 & 1.330 & \\
\hline$r\left(\mathrm{O}_{\mathrm{Z} 2}-\mathrm{H}^{\prime}\right)(\AA)$ & & 1.47 & 1.330 & 0.97 \\
\hline$r\left(\mathrm{C}^{\prime}-\mathrm{H}_{\mathrm{Z}}\right)(\AA)$ & & 1.26 & 1.323 & 1.09 \\
\hline$r\left(\mathrm{C}^{\prime}-\mathrm{H}^{\prime}(\AA)\right.$ & 1.09 & 1.28 & 1.319 & \\
\hline$r\left(\mathrm{Al}-\mathrm{O}_{\mathrm{Zl}}\right)(\AA)$ & 1.86 & 1.75 & 1.854 & 1.68 \\
\hline$r\left(\mathrm{Al}-\mathrm{O}_{\mathrm{Z} 2}\right)(\AA)$ & 1.68 & 1.75 & 1.853 & 1.86 \\
\hline$E_{\text {Act }}(\mathrm{kcal} / \mathrm{mol})$ & & 40.0 & 28.2 & \\
\hline$V_{\mathrm{TST}}\left(\mathrm{cm}^{-1}\right)$ & & $1147 i$ & $1374 \mathrm{i}$ & \\
\hline
\end{tabular}

propane with the Brønsted acid site. Figure $11 \mathrm{~b}$ shows the activated complex of propane with the zeolite cluster. This consists of the methyl carbon associated with the proton donor and acceptor sites through the two protons involved in the exchange. The transition-state structure corresponds to a saddle point in the potential energy surface with one negative force constant assigned to the rocking mode of proton exchange. The frequency associated with this mode is $1142 \mathrm{i} \mathrm{cm} \mathrm{cm}^{-1}$. The computed activation energy is $40.5 \mathrm{kcal} / \mathrm{mol}$. Zero-point energy corrections lower the barrier by $1.3 \mathrm{kcal} / \mathrm{mol}$. Selected bond 


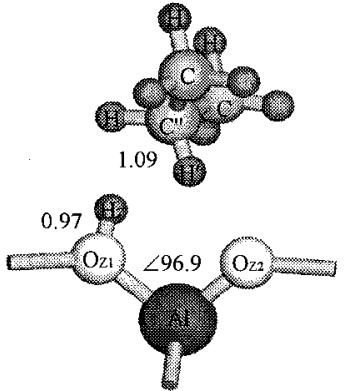

(a)

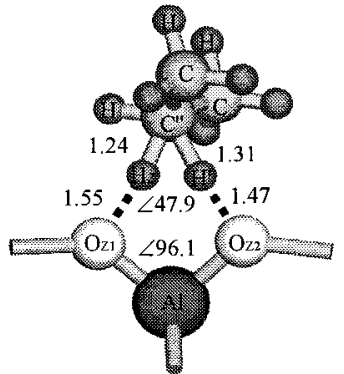

(b)

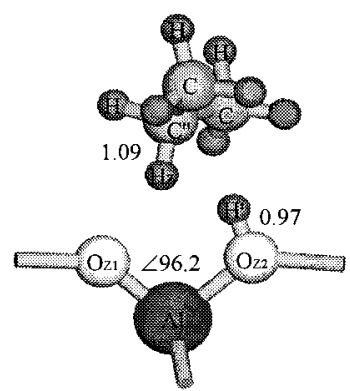

(c)

Figure 12. Dissociated species (a, c) and activated complex (b) for hydrogen exchange with methylene group of propane.

TABLE 9: Selected Bond Lengths (̊̊) and Angles (deg) of Dissociated Species and the Activated Complex for Hydrogen Exchange with the Methyl Group of Propane

\begin{tabular}{lccc}
\hline & (a) dissociated species & (b) activated complex & (c) dissociated species \\
\hline method & DFT-BH\&HLYP & DFT-BH\&HLYP & DFT-BH\&HLYP \\
basis set & $6-31 \mathrm{G}(* *++)$ & $6-31 \mathrm{G}(* *++)$ & $6-31 \mathrm{G}(* *++)$ \\
cluster size & $5 \mathrm{~T}$ & $5 \mathrm{~T}$ & $5 \mathrm{~T}$ \\
$\mathrm{O}_{\mathrm{Z1}}-\mathrm{Al}-\mathrm{O}_{\mathrm{Z} 2}(\mathrm{deg})$ & 96.9 & 95.6 & 96.1 \\
$r\left(\mathrm{O}_{\mathrm{Z} 1}-\mathrm{H}_{\mathrm{Z}}\right)(\AA)$ & 0.97 & 1.50 & 0.97 \\
$r\left(\mathrm{O}_{\mathrm{Z} 2}-\mathrm{H}^{\prime}\right)(\AA)$ & & 1.46 & 1.09 \\
$r\left(\mathrm{C}^{\prime}-\mathrm{H}_{\mathrm{Z}}\right)(\AA)$ & & 1.24 & \\
$r\left(\mathrm{C}^{\prime}-\mathrm{H}^{\prime}\right)(\AA)$ & 1.09 & 1.29 & 1.68 \\
$r\left(\mathrm{Al}-\mathrm{O}_{\mathrm{Zl}}\right)(\AA)$ & 1.86 & 1.75 & 1.86 \\
$r\left(\mathrm{Al}-\mathrm{O}_{\mathrm{Z} 2}\right)(\AA)$ & 1.68 & 1.75 & \\
$E_{\mathrm{Act}}\left(\mathrm{kcal}^{-1 \mathrm{~mol})}\right.$ & & 40.5 & \\
$V_{\mathrm{TST}}\left(\mathrm{cm}^{-1}\right)$ & & $142 \mathrm{i}$ &
\end{tabular}

TABLE 10: Selected Bond Lengths $(\AA)$ and Angles (deg) of Dissociated Species and the Activated Complex for Hydrogen Exchange with the Methylene Group of Propane

\begin{tabular}{lccc}
\hline & (a) dissociated species & (b) activated complex & (c) dissociated species \\
\hline method & DFT-BH\&HLYP & DFT-BH\&HLYP & DFT-BH\&HLYP \\
basis set & $6-31 \mathrm{G}(* *++)$ & $6-31 \mathrm{G}(* *++)$ & $6-31 \mathrm{G}(* *++)$ \\
cluster size & $5 \mathrm{~T}$ & $5 \mathrm{~T}$ & $5 \mathrm{~T}$ \\
$\mathrm{O}_{\mathrm{Z}}-\mathrm{A} 1-\mathrm{O}_{\mathrm{Z} 2}(\mathrm{deg})$ & 96.9 & 96.1 & 96.1 \\
$r\left(\mathrm{O}_{\mathrm{Z}}-\mathrm{H}_{\mathrm{Z}}\right)(\AA)$ & 0.97 & 1.55 & 0.97 \\
$r\left(\mathrm{O}_{\mathrm{Z} 2}-\mathrm{H}^{\prime}\right)(\AA)$ & & 1.47 & 1.09 \\
$r\left(\mathrm{C}^{\prime \prime}-\mathrm{H}_{\mathrm{Z}}\right)(\AA)$ & 1.09 & 1.24 & 1.68 \\
$r\left(\mathrm{C}^{\prime \prime}-\mathrm{H}^{\prime}\right)(\AA)$ & 1.86 & 1.30 & \\
$r\left(\mathrm{~A} 1-\mathrm{O}_{\mathrm{Z} 1}\right)(\AA)$ & 1.68 & 1.76 & 1.74 \\
$r\left(\mathrm{~A} 1-\mathrm{O}_{\mathrm{Z} 2}\right)(\AA)$ & & 39.2 & \\
$E_{\mathrm{Act}}\left(\mathrm{kcal}_{\mathrm{m}} / \mathrm{mol}\right)$ & & $1029 \mathrm{i}$ & \\
$V_{\mathrm{TST}}\left(\mathrm{cm}^{-1}\right)$ & &
\end{tabular}

lengths and angles for hydrogen exchange between propane and zeolite are provided in Table 9.

Figure 12 shows the proton exchange reaction between the methylene group of propane and zeolite. Parts a and c of Figure 12 depict free propane in proximity of the Brønsted acid site. Figure $12 \mathrm{~b}$ shows the activated complex of propane with the zeolite cluster. This consists of the methylene carbon associated with the proton donor and acceptor sites through the two protons involved in the exchange. The transition-state structure corresponds to a saddle point in the potential energy surface with one negative force constant assigned to the rocking mode of proton exchange. The frequency associated with this mode is $1029 \mathrm{icm}^{-1}$. The computed activation energy is $39.2 \mathrm{kcal} / \mathrm{mol}$. Zero-point energy corrections lower the barrier by $0.7 \mathrm{kcal} /$ mol. Selected bond lengths and angles for hydrogen exchange between the secondary carbon of propane and zeolite are provided in Table 10.

In situ ${ }^{1} \mathrm{H}$ MAS NMR experiments by Stepanov et al. ${ }^{49}$ measured the activation energy for hydrogen exchange between deuterated propane and the acidic protons in $\mathrm{H}-\mathrm{ZSM}-5$. For the methyl group, they measured a value of $26 \pm 2 \mathrm{kcal} / \mathrm{mol}$, whereas they found a higher value of $28 \pm 2 \mathrm{kcal} / \mathrm{mol}$ for the methylene group. Although in spirit this is the opposite of our predicted trend, the experimental deviation reported more than accounts for the differences in the two measured values.

As a final case in a series of hydrogen exchange reactions, we consider the activation of benzene by the acidic proton in zeolite. Figure 13 shows the hydrogen exchange reaction between benzene and zeolite. Parts a and c of Figure 13 depict free benzene in proximity of the Brønsted acid site. No stable structure was found for the adsorption complex of benzene with the Brønsted acid site. Figure 13b shows the activated complex of benzene with the zeolite cluster. This consists of benzene associated with the proton donor and acceptor sites through the two protons involved in the exchange. The transition-state structure corresponds to a saddle point in the potential energy surface with one negative force constant assigned to the rocking mode of proton exchange. The imaginary frequency of this mode is $840 \mathrm{i} \mathrm{cm}^{-1}$. The computed energy barrier is $33.6 \mathrm{kcal} / \mathrm{mol}$. ZPE corrections reduce the observed activation energy by 6.6 $\mathrm{kcal} / \mathrm{mol}$. Selected bond lengths and angles for hydrogen exchange between benzene and zeolite are provided in Table 11 along with a comparison with previous related studies. Experimental measurements of the activation of benzene in 


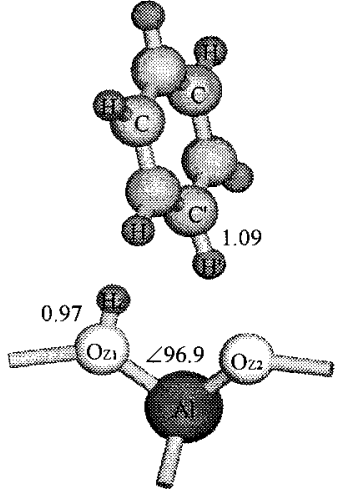

(a)

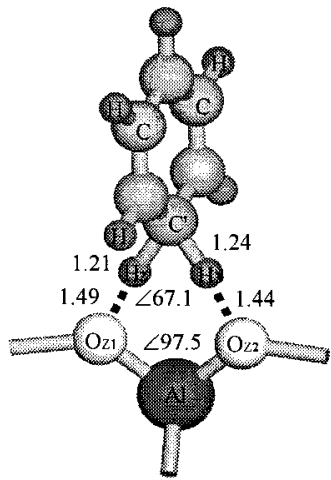

(b)

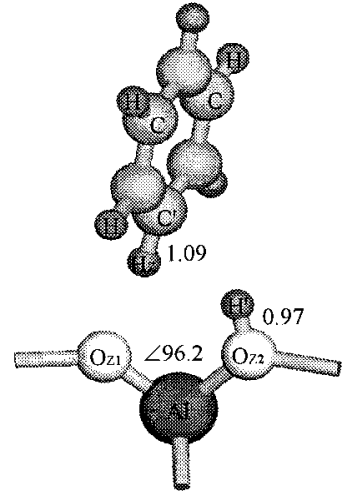

(c)

Figure 13. Dissociated species (a, c) and activated complex (b) for hydrogen exchange with benzene.

TABLE 11: Selected Bond Lengths (̊̊) and Angles (deg) of Dissociated Species and the Activated Complex for Hydrogen Exchange with Benzene

\begin{tabular}{|c|c|c|c|c|}
\hline \multirow[b]{2}{*}{ method } & \multirow{2}{*}{$\begin{array}{c}\text { (a) dissociated species } \\
\text { DFT-BH\&HLYP }\end{array}$} & \multicolumn{2}{|c|}{ (b) activated complex } & \multirow{2}{*}{$\begin{array}{c}\text { (c) dissociated species } \\
\text { DFT-BH\&HLYP }\end{array}$} \\
\hline & & DFT-BH\&HLYP & DFT-BLYP & \\
\hline basis set & $6-31 \mathrm{G}(* *++)$ & $6-31 \mathrm{G}(* *++)$ & $6-31 \mathrm{G}(* *)$ & $6-31 \mathrm{G}(* *++)$ \\
\hline cluster size & $5 \mathrm{~T}$ & $5 \mathrm{~T}$ & $3 \mathrm{~T}$ & $5 \mathrm{~T}$ \\
\hline reference & this work & this work & 25 & this work \\
\hline $\mathrm{O}_{\mathrm{Zl}}-\mathrm{Al}-\mathrm{O}_{\mathrm{Z} 2}(\mathrm{deg})$ & 96.9 & 97.5 & & 96.1 \\
\hline$r\left(\mathrm{O}_{\mathrm{ZI}}-\mathrm{H}_{\mathrm{Z}}\right)(\AA)$ & 0.97 & 1.49 & 1.48 & \\
\hline$r\left(\mathrm{O}_{\mathrm{Z2}}-\mathrm{H}^{\prime}\right)(\AA)$ & & 1.44 & 1.49 & 0.97 \\
\hline$r\left(\mathrm{C}^{\prime}-\mathrm{H}_{\mathrm{Z}}\right)(\AA)$ & & 1.24 & 1.23 & 1.09 \\
\hline$r\left(\mathrm{C}^{\prime}-\mathrm{H}^{\prime}\right)(\AA)$ & 1.09 & 1.21 & 1.22 & \\
\hline$r\left(\mathrm{Al}-\mathrm{O}_{\mathrm{Z}}\right)(\AA)$ & 1.86 & 1.75 & 1.81 & 1.68 \\
\hline$r\left(\mathrm{Al}-\mathrm{O}_{\mathrm{Z} 2}\right)(\AA)$ & 1.68 & 1.74 & 1.80 & 1.86 \\
\hline$E_{\text {Act }}(\mathrm{kcal} / \mathrm{mol})$ & & 33.6 & 21.2 & \\
\hline$V_{\mathrm{TST}}\left(\mathrm{cm}^{-1}\right)$ & & $840 \mathrm{i}$ & & \\
\hline
\end{tabular}

$\mathrm{H}-\mathrm{ZSM}-5$ yield a value of $14.4 \mathrm{kcal} / \mathrm{mol}$, significantly below the $27.0 \mathrm{kcal} / \mathrm{mol} \mathrm{ZPE}$-corrected barrier predicted for our constrained cluster model zeolite. ${ }^{28}$ Again, the experimental value provides an average view of hydrogen exchange with all available hydrogen on the zeolite surface, whereas our model considers only one reactive site.

On the basis of the results of our electronic structure calculations, we seek to develop some qualitative relation between the structure of the molecular species $\mathrm{R}-\mathrm{H}$ and its ability to exchange hydrogen with the Brønsted acid site. Note that in each of Figures 8-12, the mechanism for hydrogen exchange between $\mathrm{R}-\mathrm{H}$ and the Brønsted acid site requires lengthening of the $\mathrm{R}-\mathrm{H}^{\prime}$ bond in order to reach the transition state of the reaction. In the case of dihydrogen, the $\mathrm{H}-\mathrm{H}^{\prime}$ bond length stretches from $0.74 \AA$ at the reactant state to $1.05 \AA$ at the transition state. For methane, the $\mathrm{CH}_{3}-\mathrm{H}^{\prime}$ bond lengthens from $1.09 \AA$ at the reactant state to $1.28 \AA$ at the transition state. Similar trends are seen for the remaining hydrocarbons in the series $\mathrm{R}-\mathrm{H}$.

We propose that some relationship lies between the weakening of the $\mathrm{R}-\mathrm{H}^{\prime}$ bond and the ability of a species $\mathrm{R}-\mathrm{H}$ to effect hydrogen exchange. We define the energy due to the deprotonation of a proton from a species $\mathrm{R}-\mathrm{H}, E_{\mathrm{DP}}$, as its ability to donate a proton

$$
\mathrm{R}-\mathrm{H} \rightarrow \mathrm{R}^{-}+\mathrm{H}^{+} \quad E_{\mathrm{DP}}
$$

Figure 14 gives a plot of the deprotonation energy versus activation energy for the series of species $\mathrm{R}-\mathrm{H}\left(\mathrm{R}=\mathrm{H}, \mathrm{CH}_{3}\right.$, $\mathrm{C}_{2} \mathrm{H}_{5}, \mathrm{C}_{3} \mathrm{H}_{7}, \mathrm{C}_{6} \mathrm{H}_{5}$ ) considered in this study. The values of $E_{\mathrm{DP}}$ were computed for the appropriate ionic and neutral species at

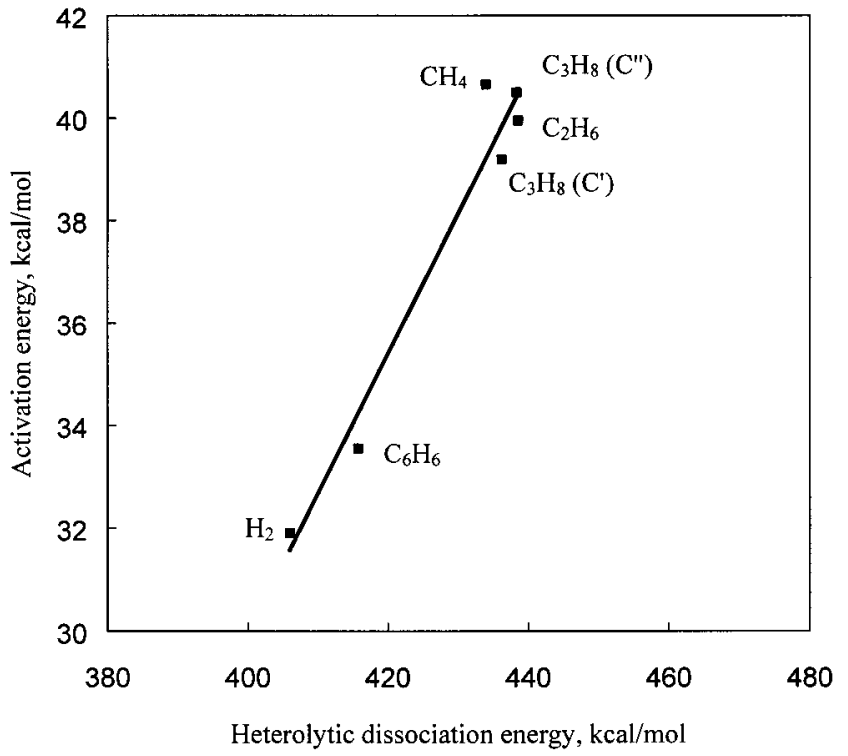

Figure 14. Deprotonation energy versus activation energy for hydrogen exchange with $\mathrm{R}-\mathrm{H}$.

the MP2/6-31G**++ level of theory. It is evident that to a first approximation the activation barrier, $E_{\mathrm{Act}}$, increases with an increase in the deprotonation energy, $E_{\mathrm{DP}}$, of the activating species. One interpretation of this trend is that the early part of the reaction coordinate is dominated by weakening of the $\mathrm{R}-\mathrm{H}^{\prime}$ bond. One measure of the ability of this bond to be weakened is the deprotonation energy of the species. The greater the ability of a species to donate protons, the lower the activation barrier for hydrogen exchange. 




Figure 15. Computed reaction rate constants versus temperature for hydrogen exchange with $\mathrm{R}-\mathrm{H}$.

Rate Constants for Hydrogen Exchange. Figure 15 shows the dependence of the reaction rate constants, $k$, on temperatures for the each of the hydrogen exchange reactions involving $\mathrm{R}-\mathrm{H}$. As expected, those species with the lowest activation barriers (e.g., $\mathrm{H}_{2}, \mathrm{C}_{6} \mathrm{H}_{6}$ ) boast the highest rates for hydrogen exchange. Note that for those species whose activation barriers are similar in magnitude (the series $\mathrm{CH}_{4}, \mathrm{C}_{2} \mathrm{H}_{6}, \mathrm{C}_{3} \mathrm{H}_{8}$ ) the prexponential factor determines the difference in the computed rate.

Additional calculations were performed to estimate the contribution of quantum mechanical tunneling to the overall reaction rate constant for hydrogen hopping and hydrogen exchange. Tunneling corrections were computed by fitting the energy minima, transition-state energy, and transition-state frequency with an asymmetric one-dimensional Eckart function. ${ }^{50}$ On the basis of our calculations, the largest contribution of proton tunneling to proton hopping and hydrogen exchange is seen at temperatures below $400 \mathrm{~K}$. At conditions of interest, tunneling does not appear to be an important factor. For a more rigorous treatment of quantum tunneling effects, we recommend the semiclassical tunneling approximations that require energy, gradient, and Hessian information along the minimum energy path. ${ }^{51}$ These methods demand a much more detailed understanding of the potential energy hypersurface but provide a more accurate estimate of the contribution of proton tunneling to the overall reaction rate.

\section{Conclusions}

Using density functional theory, we have considered several different pathways for proton migration about the Brønsted acid site in model $\mathrm{H}-\mathrm{ZSM}-5$. In the absence of water, the acidic proton "hops" or migrates between two of the four $\mathrm{O}$ atoms surrounding an aluminum center with an activation barrier of $28 \mathrm{kcal} / \mathrm{mol}$. During proton transfer, the $\mathrm{O}$ atoms stretch closer together in order to stabilize the transition state. This is revealed by a 13.4-degree decrease in the $\mathrm{O}-\mathrm{Al}-\mathrm{O}$ bond angle. This points to the importance of framework flexibility. The presence of adsorbed water bridges the proton donor and acceptor sites during proton transfer, reducing the apparent activation barrier by $24 \mathrm{kcal} / \mathrm{mol}$ and increasing apparent rates by factors of $10^{26}$ at low temperature and $10^{4}$ at high temperature. Employing a model experimental system, we have shown that an experimentally undetectable quantity of water can significantly affect the kinetics of proton migration. Thus, water-assisted proton transfer provides a kinetically favorable alternative mechanism for proton migration about the Brønsted acid site.

The kinetics of hydrogen exchange in zeolite varies with the identity of the hydrogen-bearing chemical species. Through the systematic application of density functional theory and the constrained cluster method to a series of hydrogen exchange reactions, we are able to obtain a qualitative relationship between the activation energy for exchange and chemical properties of the gas-phase species. Also, a comparison of computed exchange rates to that of dry proton hopping give a measure of the feasibility of exchange as an alternative pathway for protons to migrate about the Al tetrahedron.

Acknowledgment. This work was supported by the Office of Industrial Technology of the U.S. DOE under contract number DE-AC03-SF763098. Additional support was provided by a graduate research fellowship from the National Science Foundation. Computational resources were provided by the National Energy Resource Supercomputer Center (NERSC). We thank Mark Rice, Dr. François Gilardoni, and Dr. John Nicholas for very thoughtful and stimulating conversations.

\section{References and Notes}

(1) Neurock, M.; van Santen, R. A. Catal. Today 1999, 50, 445-450.

(2) Bates, S. P.; van Santen, R. A. Adv. Catal. 1998, 42, 1-114.

(3) Nicholas, J. B. Top. Catal. 1997, 38, 377-390.

(4) Van Santen, R. A. Catal. Today 1997, 38, 157-171.

(5) Redondo, A.; Hay, P. J. J. Phys. Chem. 1993, 97, 11754-11761.

(6) Sauer, J.; Kölmel, C. M.; Hill, J. R.; Ahlrichs, R. Chem. Phys. Lett. 1989, 164, 193-198.

(7) Sauer, J. In Modeling of Structure and Reactivity in Zeolites; Catlow, C. R. A., Ed.; Academic Press: San Diego, CA, 1992.

(8) Sauer, J.; Sierka, M.; Haase, F. In Transition State Modeling for Catalysis; ACS Symposium Series 721; Truhlar, D. G.; Morokuma, K., Eds.; American Chemical Society: Washington, DC, 1999; p 359.

(9) Zygmunt, S. A.; Mueller, R. M.; Curtiss, L. A.; Iton, L. E. J. Mol. Struct. 1998, 430, 9-16.

(10) Gonzales, N. O.; Bell, A. T.; Chakraborty, A. K. J. Phys. Chem. B 1997, 101, 10058-10064.

(11) Rice, M. J.; Chakraborty, A. K.; Bell, A. T. J. Phys. Chem. B 1998 , $102,7498-7504$.

(12) Gale, J. D. Top. Catal. 1996, 3, 169-194.

(13) Greatbanks, S. P.; Hillier, I. H.; Burton, N. A. J. Chem. Phys. 1996, 105, 3770-3776

(14) Zygmunt, S. A.; Curtiss, L. A.; Iton, L. E.; Erhardt, M. K. J. Phys. Chem. 1996, 100, 6663-6671.

(15) Krossner, M.; Sauer, J. J. Phys. Chem. 1996, 100, 6199-6211.

(16) Jobic, H.; Tuel, A.; Krossner, M.; Sauer, J. J. Phys. Chem. 1996, 100, 19545-19550.

(17) Gale, J. D.; Catlow, C. R. A.; Carruthers, J. R. Chem. Phys. Lett. 1993, 216, 155-161.

(18) Blaszkowski, S. R.; van Santen, R. A. J. Phys. Chem. 1995, 99, 11728-11738.

(19) Bates, S.; Dwyer, J. J. Mol. Struct. 1994, 112, 57-65.

(20) Haase, F.; Sauer, J. J. Am. Chem. Soc. 1995, 117, 3780-3789.

(21) Allavena, M.; Kassab, E.; Evleth, E. J. Mol. Struct. 1994, 325, 8593.

(22) Evleth, E. M.; Kassab, E.; Sierra, L. R. J. Phys. Chem. 1994, 98 $1421-1426$

(23) Blaszkowski, S. R.; Nascimento, M. A. C.; van Santen, R. A. J. Phys. Chem. 1996, 100, 3463-3472.

(24) Blaszkowski. S. R.; Jansen, A. P. J.; Nascimento, M. A. C.; van Santen, R. A. J. Phys. Chem. 1994, 98, 12938-12944.

(25) Kramer, G. J.; van Santen, R. A. J. Am. Chem. Soc. 1995, 117, 1766-1776.

(26) Truong, T. N. J. Phys. Chem. B 1997, 101, 2750-2752.

(27) Esteves, P. M.; Nascimento, A. C.; Mota, J. A. J. Phys. Chem. B 1999, 103, 10417-10420.

(28) Beck, L. W.; Xu, T.; Nicholas, J. B.; Haw, J. F. J. Am. Chem. Soc. 1995, 117, 11594-11595.

(29) Sarv, P.; Tuherm, T.; Lippmaa, E.; Keskinen, K.; Root, A. J. Phys. Chem. 1995, 99, 13763-13768. 
(30) Baba, T.; Komatsu, N.; Ono, Y. J. Phys. Chem. B 1998, 102, 804808

(31) Ernst, H.; Freude, D.; Mildner, T.; Pfeifer, H. In Proceedings of the 12th International Zeolite Conference; Materials Research Society: Warrendale, PA, 1999; p 2955.

(32) Hunger, M. Catal. Rev. 1997, 39, 345-393.

(33) Bonn, M.; Bakker, H. J.; Domen, K.; Hirose, C.; Kleyn, A. W.; van Santen, R. A. Catal. Rev. 1998, 40, 127-173.

(34) Higazy, A. A.; Kassem, M. E.; Sayed, M. B. J. Phys. Chem. Solids 1992, 53, 549-554

(35) Olson, D. H.; Kokotallo, G. T.; Lawton, S. L.; Meier, W. M. J. Phys. Chem. 1981, 85, 2238-2243.

(36) Parr, R. G.; Yang, W. Density-Functional Theory of Atoms and Molecules; Oxford University Press: Oxford, U.K., 1989.

(37) Becke, A. D. J. Chem. Phys. 1993, 98, 1372-1377.

(38) Becke, A. D. J. Chem. Phys. 1993, 98, 5648-5652

(39) Lee, C.; Yang, W.; Parr, R. G. Phys. Rev. B 1988, 37, 785.

(40) Perdew, J. P. In Electronic Structure of Solids; Ziesche, P., Eschrig, H., Eds.; Adademie Verlag: Berlin, 1991.
(41) Becke, A. D. Phys. Rev. A 1988, 38, 3098-3100.

(42) Truong, T. N.; Duncan, W. T.; Bell, R. L. In Chemical Applications of Density-Functional Theory; Laird, B. B., Ross, R. B., Ziegler, T., Eds.; American Chemical Society: Washington, DC, 1996.

(43) Jaguar 3.5, Schrödinger, Inc., Portland, OR, 1998.

(44) McQuarrie, D. A. Statistical Mechanics; HarperCollins Publisher Inc.: New York, 1973.

(45) Deem, M. W.; Newsam, J. M.; Creighton, J. A. J. Am. Chem. Soc. 1992, 114, 7198-7207.

(46) Ison, A.; Gorte, R. J. J. Catal. 1984, 89, 150-158.

(47) Biscardi, J. A.; Meitzner, G. D.; Iglesia, E. J. Catal. 1998, 179, 192-202.

(48) Larson, J. G.; Hall, K. H. J. Phys. Chem. 1965, 69, 3080-3089.

(49) Stepanov, A. G.; Ernst, H.; Freude, D. Catal. Lett. 1998, 54, 1-4.

(50) Eckart, C. Phys. Rev. 1930, 35, 1303.

(51) Duncan, W. T.; Bell, R. L.; Truong, T. N. J. Comput. Chem. 1998, $19,1039-1052$ 